OPEN ACCESS

Edited by:

Jose Eduardo Villarreal Barajas, Royal Devon and Exeter Hospital,

United Kingdom

Reviewed by: Kevin Martell,

University of Calgary, Canada Yinyan Wang,

Capital Medical University, China

${ }^{*}$ Correspondence:

Yu Zeng

zengyu@csu.edu.cn

Zhixiong Liu

zhixiongliu@csu.edu.cn

Specialty section:

This article was submitted to

Radiation Oncology,

a section of the journal

Frontiers in Oncology

Received: 28 June 2021

Accepted: 23 September 2021

Published: 14 October 2021

Citation:

Yi Z, Long L, Zeng Y and Liu Z (2021)

Current Advances and Challenges in

Radiomics of Brain Tumors.

Front. Oncol. 11:732196.

doi: 10.3389/fonc.2021.732196

\section{Current Advances and Challenges in Radiomics of Brain Tumors}

\author{
Zhenjie Yi ${ }^{1,2,3}$, Lifu Long ${ }^{2}$, Yu Zeng ${ }^{1,3 *}$ and Zhixiong Liu ${ }^{1,3 *}$ \\ ${ }^{1}$ Department of Neurosurgery, Xiangya Hospital, Central South University, Changsha, China, ${ }^{2}$ XiangYa School of Medicine, \\ Central South University, Changsha, China, ${ }^{3}$ National Clinical Research Center for Geriatric Disorders, Xiangya Hospital, \\ Central South University, Changsha, China
}

Imaging diagnosis is crucial for early detection and monitoring of brain tumors. Radiomics enable the extraction of a large mass of quantitative features from complex clinical imaging arrays, and then transform them into high-dimensional data which can subsequently be mined to find their relevance with the tumor's histological features, which reflect underlying genetic mutations and malignancy, along with grade, progression, therapeutic effect, or even overall survival (OS). Compared to traditional brain imaging, radiomics provides quantitative information linked to meaningful biologic characteristics and application of deep learning which sheds light on the full automation of imaging diagnosis. Recent studies have shown that radiomics' application is broad in identifying primary tumor, differential diagnosis, grading, evaluation of mutation status and aggression, prediction of treatment response and recurrence in pituitary tumors, gliomas, and brain metastases. In this descriptive review, besides establishing a general understanding among protocols, results, and clinical significance of these studies, we further discuss the current limitations along with future development of radiomics.

Keywords: radiomics, radiogenomics, glioma, pituitary tumor, brain metastases

\section{INTRODUCTION}

Brain and other CNS tumors, including gliomas, pituitary tumors, and others such as brain metasteses, mainly occur in lung cancer and breast cancer patients. These tumors stand out for their high diversity and heterogeneity, along with dismal prognosis, ranking them among the top 10 causes of cancer deaths, accounting for a significant proportion of the deaths in men less than 40

\footnotetext{
Abbreviations: AUC, area under the curve; BM, brain metastases; CAD, computer-aided diagnosis and detection; CADe, computer-aided detection; CBV, cerebral blood volume; CCC, concordance correlation coefficient; CE-T1WI, contrastenhanced T1-weighted MRI; CNN, convolutional neural network; DSC, dynamic susceptibility contrast; DTI, diffusion tensor imaging; DWI, diffusion-weighted imaging; EGFR, epidermal growth factor receptor; FLAIR, fluid-attenuated inversion recovery; GBM, glioblastoma; HGG, high-grade glioma; IDH, isocitrate dehydrogenase; LASSO, least absolute shrinkage and selection operator; LGG, low-grade glioma; MGMT, O-6-methylguanine-DNA methyltransferase; MRI, magnetic resonance imaging; mRMR, minimum redundancy maximum relevance algorithm; MRS, magnetic resonance spectroscopy; NFPA, nonfunctioning pituitary adenoma; OS, overall survival; PA, pituitary adenoma; PCA, principal component analysis; PCNSL, primary central nervous system lymphoma; PD, progressive disease; PFS, progression-free survival; PsP, Pseudoprogression; PWI, perfusion-weighted imaging; RECIST, Response Evaluation Criteria in Solid Tumours; RF, random forest; RFE, recursive feature elimination; ROC, receiver operating characteristic curve; RQS, radiomics quality score; SAM, significance analysis of microarrays; SVM, support vector machine; TRC, treatment-related changes.
} 
years and women less than 20 years in the United States in 2018 (1), and it is estimated that they will cause 18,600 deaths in 2021.

Clinical radiology is a routinely performed examination for patients who are suspicious of brain or other CNS tumors; recently more and more sophisticated analytic methods have sprung up which supplement traditional imaging techniques. Based on the imaging techniques and incorporated with computer vision and machine learning (2), radiomics was born. Radiomics first appeared in Philippe's review in 2012 (3), initially as an extended technique of computer-aided diagnosis and detection (CAD) systems. The term radiomics refers to the refining of a large mass of quantitative features from complex clinical imaging arrays, then transforming them into highdimensional data which can subsequently be mined to find their relevance with the tumor's histological features, which reflect underlying genetic mutations and malignancy, along with grade, progression, therapeutic effect, or even overall survival (OS) (4). Deep learning is a branch of machine learning, and machine learning is the necessary path to realize artificial intelligence (AI). The concept of deep learning originated from the study of neural networks that simulate the human brain. In recent years, we have seen a blossoming in AI development, with more intelligent algorithms such as deep learning bringing the possibility of realizing fully automatic image capturing and reading processes. Compared to traditional manual radiology practice requiring trained physicians to deal with large quantities of information, which is labor intensive, subjective, and qualitative, radiomics is able to use AI methods to provide automatic, objective, and quantitative data with high efficiency. In this review, we focus on radiomics and extended imaging techniques. The general clinical applications of these noninvasive methods are shown (Figure 1).

\section{Clinical Application}

Early accurate diagnosis and classification are crucial in prolonging the patient's survival time. The application of radiomics has been initiated in clinical oncology early diagnosis, since its ability to analyze the combination of numerous quantitative features provides the possibility to unravel the underlying pathophysiology that is hard to be perceived by radiologists' eyes and avoid subjective misreading. The general workflow of radiomics involves several discrete steps: imaging, segmentation, feature extraction, feature selection, machine learning, and validation (5). Segmentation is using a series of algorithms to delineate regions of interest (ROIs), which refers to the tumor and its surrounding abnormality from other tissue, and then further subdividing the legion by its intra-heterogeneity to facilitate the next steps. Accurate segmentation is a key step from image processing to quantitative analysis, acting as a prerequisite for the subsequent diagnostic tasks like defining the location, extent of radiation, and tumor feature extraction, and is the most challenging step due to high heterogeneity and irregularity of brain tumors. Feature extraction refers to the use of existing features to calculate a feature set with a higher degree of abstraction, and also refers to an algorithm for calculating a certain feature. Then the extracted features will go through feature selection, which

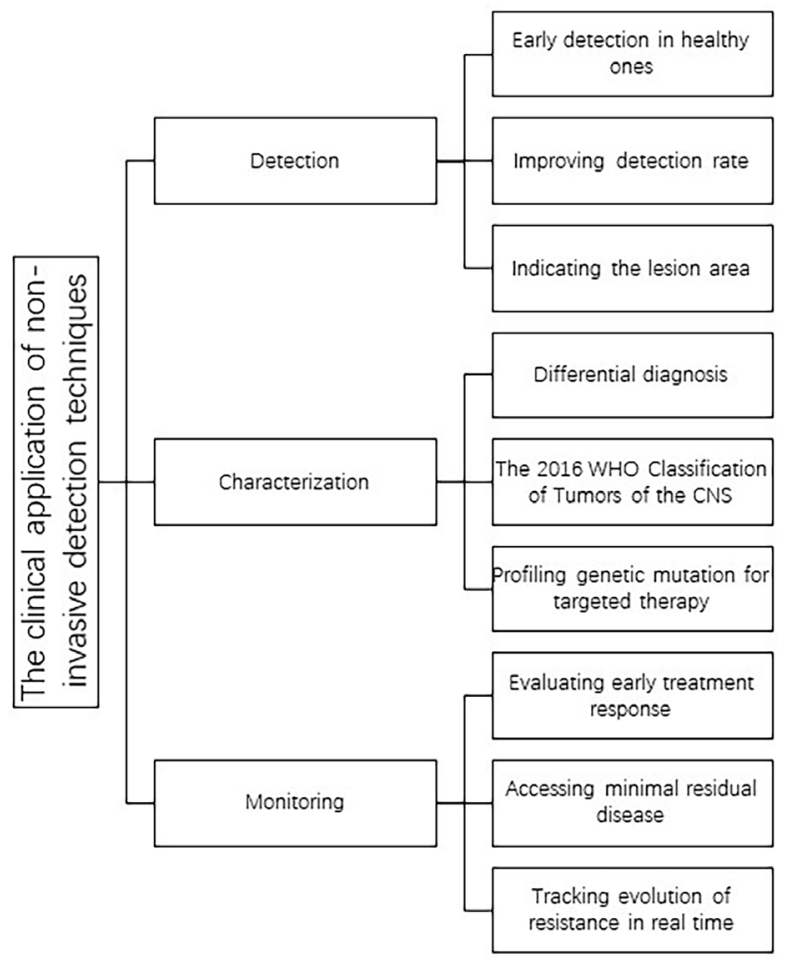

FIGURE 1 | The clinical application of the noninvasive detection techniques.

aims at reducing dimensionality and the difficulty of learning tasks to improve the efficiency of the model. The top features will be integrated with clinical results and/or pathological results, together as input into machine learning methods to build prediction or classification models.

The main clinical tasks of radiomics lie in three parts: detection, characterization, and monitoring. By the help of computer-aided detection (CADe), the suspicious area of the image can be highlighted and some features indicating early cancer lesions can be detected, which reduce observational oversights and improve the speed of interpretation $(6,7)$. Most radiomics models are served for characterization, including diagnostic tasks (differential diagnosis, malignancy, WHO CNS classification, specific genetic mutation status, and treatment effect) and predictive/prognostic tasks (treatment effect, OS/ PFS, complication, and tumor recurrence). Monitoring is also significant within clinical practice in evaluating the progression of tumor and the effect of treatment. Traditional protocols to assess the tumor progression, recommended by institutions like Response Evaluation Criteria in Solid Tumors (RECIST) and WHO, are usually defined by the size of tumor (8), which omits much geometry and material information detected by advanced radiological instruments and also oversimplifies the indicators on tumor burden. The emergence of AI-monitoring may help radiologists to establish more sophisticated quantitative protocols towards tumor burden evaluation.

MRI acts as a key part and is usually the first choice in radiological diagnosis of brain tumors. First, MRI has an 
TABLE 1 | Radiomic.

\begin{tabular}{|c|c|c|c|c|c|c|c|c|}
\hline Study & $\begin{array}{l}\text { No. of } \\
\text { patients } \\
\text { involved } \\
\text { (Training/ } \\
\text { Test) }\end{array}$ & $\begin{array}{l}\text { General } \\
\text { purpose }\end{array}$ & $\begin{array}{c}\text { CT or MRI con- } \\
\text { trast(s) }\end{array}$ & $\begin{array}{l}\text { Segmentation } \\
\text { method }\end{array}$ & $\begin{array}{l}\text { Nomber of } \\
\text { features } \\
\text { (extraction/ } \\
\text { selection) }\end{array}$ & $\begin{array}{l}\text { Feature } \\
\text { selection } \\
\text { method }\end{array}$ & $\begin{array}{l}\text { Classification } \\
\text { method }\end{array}$ & $\begin{array}{c}\text { Performance (Training/ } \\
\text { Test) }\end{array}$ \\
\hline $\begin{array}{l}\text { Yae Won } \\
\text { Park et al. } \\
\text { (30) }\end{array}$ & $141 / 36$ & $\begin{array}{l}\text { To predict the DA } \\
\text { response in } \\
\text { prolactinoma } \\
\text { patients }\end{array}$ & $\mathrm{T} 2 \mathrm{WI}$ & $\begin{array}{l}\wedge \wedge 3 D \text { Slicer } \\
\text { software }\end{array}$ & 107/n.a. & / & $\begin{array}{l}\text { soft voting (RF, } \\
\text { light gradient } \\
\text { boosting machine, } \\
\text { extra-trees, } \\
\text { quadratic } \\
\text { discrimination } \\
\text { analysis, and linear } \\
\text { discrimination } \\
\text { analysis) }\end{array}$ & \#0.81/0.81 (AUC) \\
\hline $\begin{array}{l}\text { Yang } \\
\text { Zhang et al. } \\
(40)\end{array}$ & 50/n.a. & $\begin{array}{l}\text { To predict } \\
\text { progression or } \\
\text { reccurence in } \\
\text { NFPAs }\end{array}$ & $\begin{array}{l}\text { CE-T1WI and } \\
\text { T2WI }\end{array}$ & $\begin{array}{l}\wedge \wedge \text { fuzzy C- } \\
\text { mean (FCM) } \\
\text { clustering } \\
\text { algorithm }\end{array}$ & $107 / 3$ & SVM & SVM & ${ }^{\star \star \star} 0.78 /$ n.a.(AUC) \\
\hline $\begin{array}{l}\text { Andrei } \\
\text { Mouraviev } \\
\text { et al. (117) }\end{array}$ & 87/n.a. & $\begin{array}{l}\text { To predict local } \\
\text { recurrence } \\
\text { following SRS }\end{array}$ & $\begin{array}{l}\text { CE-T1WI and } \\
\text { FLAIR }\end{array}$ & $\begin{array}{l}\wedge \wedge \text { Elastix } \\
\text { software }\end{array}$ & $440 / 12$ & $\begin{array}{l}\text { Random } \\
\text { forest feature } \\
\text { importance } \\
\text { (RFI) }\end{array}$ & $\mathrm{RF}$ & \#0.793/n.a. (AUC) \\
\hline $\begin{array}{l}\text { Kniep, H } \\
\text { et al.(113) }\end{array}$ & 189/n.a. & $\begin{array}{l}\text { To predict tumor } \\
\text { type in different } \\
\text { BM with } \\
\text { unknown primary } \\
\text { lesion }\end{array}$ & $\begin{array}{l}\text { CE-T1WI, T1WI } \\
\text { and FLAIR }\end{array}$ & $\begin{array}{l}\text { ^Analyze } 11.0 \\
\text { Software }\end{array}$ & $1423 / 20$ & Decision tree & RF & $\begin{array}{l}{ }^{\star} 0.64(\mathrm{NSCLC})-0.82(\mathrm{MM}) / \\
\text { n.a.(AUC) }\end{array}$ \\
\hline $\begin{array}{l}\text { Peng, LK } \\
\text { et al. (116) }\end{array}$ & 66/n.a. & $\begin{array}{l}\text { To predict } \\
\text { diagnosing } \\
\text { treatment effect } \\
\text { after stereotactic } \\
\text { radiosurgery }\end{array}$ & $\begin{array}{l}\text { CE-T1WI and } \\
\text { FLAIR }\end{array}$ & $\begin{array}{l}\wedge \wedge \text { a } \\
\text { multiparametric } \\
\text { deep learning } \\
\text { (MPDL) network }\end{array}$ & $51 / 5$ & IsoSVM & IsoSVM & ${ }^{\star \star} 0.81 /$ n.a.(AUC) \\
\hline $\begin{array}{l}\text { Ji Eun Park } \\
\text { et al. (73) }\end{array}$ & $85 / 35$ & $\begin{array}{l}\text { To predict core } \\
\text { signaling } \\
\text { pathways in IDH } \\
\text { wild-type GBM }\end{array}$ & $\begin{array}{l}\text { T1WI, T2WI, DWI, } \\
\text { FLAIR, CE-T1WI, } \\
\text { and DSC }\end{array}$ & $\begin{array}{l}\text { ^^MITK } \\
\text { software }\end{array}$ & $\begin{array}{l}\text { 71/5(RTK), 17/ } \\
\text { 5(P53), 35/5 } \\
\text { (retinoblastoma) }\end{array}$ & $\begin{array}{l}\text { t-test, } \\
\text { LASSO, RF }\end{array}$ & Logistic regression & $\begin{array}{l}\text { (3-fold CV)0.87/0.88(RTK), } \\
\text { 0.80/0.76(p53), 0.84/0.81 } \\
\text { (retinoblastoma pathway) } \\
\text { (AUC) }\end{array}$ \\
\hline $\begin{array}{l}\text { Pascal O. } \\
\text { Zinn et al. } \\
(65)\end{array}$ & $\begin{array}{l}46 / 47 \\
(\mathrm{GBM}) \\
40 / \\
\text { n.a.(mice) }\end{array}$ & $\begin{array}{l}\text { To establish } \\
\text { causality between } \\
\text { POSTN status } \\
\text { and MRI- } \\
\text { extracted } \\
\text { radiomic-features } \\
\text { in GBM }\end{array}$ & $\begin{array}{l}\text { FLAIR and CE- } \\
\text { T1WI }\end{array}$ & $\begin{array}{l}\wedge \wedge 3 D \text { Slicer } \\
\text { software }\end{array}$ & $\begin{array}{l}2480 / 48 \\
\text { (GBM), 17(mice) }\end{array}$ & LASSO & $\begin{array}{l}\text { Binary logistic } \\
\text { regression }\end{array}$ & $\begin{array}{l}\text { **76.56\%/n.a.(GBM), } \\
92.26 \% / \text {.a.(mice)(AUC) }\end{array}$ \\
\hline $\begin{array}{l}\text { Chia-Feng } \\
\text { Lu et al. } \\
\text { (46) }\end{array}$ & $214 / 70$ & $\begin{array}{l}\text { To stratify the } \\
\text { molecular } \\
\text { subtypes of } \\
\text { gliomas }\end{array}$ & $\begin{array}{l}\text { CE-T1WI, FLAIR, } \\
\text { T2WI, and DWI }\end{array}$ & $\wedge \wedge$ n.a. & $\begin{array}{l}39212 /(20- \\
1960)\end{array}$ & $\begin{array}{l}\text { Two- } \\
\text { sample t-test } \\
\text { with pooled } \\
\text { variance } \\
\text { estimate }\end{array}$ & SVM & $\begin{array}{l}\text { *87.7\%-96.1\%/80.0\%- } \\
91.7 \% \text { (accuracy) }\end{array}$ \\
\hline $\begin{array}{l}\text { Robin } \\
\text { Gutsche } \\
\text { et al. (47) }\end{array}$ & 50/n.a. & $\begin{array}{l}\text { To evaluate the } \\
\text { repeatability of } \\
\text { feature-based } \\
\text { FET PET } \\
\text { radiomics and } \\
\text { investigate IDH } \\
\text { genotype on } \\
\text { feature } \\
\text { repeatability }\end{array}$ & FET PET & $\wedge \wedge \wedge \mathrm{TBR} \geq 1.6$ & $1302 / 297$ & $\begin{array}{l}\text { intraclass } \\
\text { correlation } \\
\text { coefficient }\end{array}$ & n.a. & n.a. \\
\hline $\begin{array}{l}\text { Yoon } \\
\text { Seong Choi } \\
\text { et al. (48) }\end{array}$ & $\begin{array}{l}727 / 439 \\
(129 \\
\text { internal } \\
\text { and } 310 \\
\text { external) }\end{array}$ & $\begin{array}{l}\text { To predict the } \\
\text { IDH status of } \\
\text { gliomas }\end{array}$ & $\begin{array}{l}\text { CE-T1WI, T2WI } \\
\text { and FLAIR }\end{array}$ & $\wedge \wedge \wedge \mathrm{CNN}$ & $24 / 20$ & CNN & CNN & $\begin{array}{l}{ }^{* *} 0.96 / 0.94 \text { (internal), } 0.86 \\
\text { (external)(AUC) }\end{array}$ \\
\hline
\end{tabular}


TABLE 1 | Continued

\begin{tabular}{|c|c|c|c|c|c|c|c|c|}
\hline Study & $\begin{array}{c}\text { No. of } \\
\text { patients } \\
\text { involved } \\
\text { (Training/ } \\
\text { Test) }\end{array}$ & $\begin{array}{l}\text { General } \\
\text { purpose }\end{array}$ & $\begin{array}{l}\text { CT or MRI con- } \\
\text { trast(s) }\end{array}$ & $\begin{array}{l}\text { Segmentation } \\
\text { method }\end{array}$ & $\begin{array}{l}\text { Nomber of } \\
\text { features } \\
\text { (extraction/ } \\
\text { selection) }\end{array}$ & $\begin{array}{l}\text { Feature } \\
\text { selection } \\
\text { method }\end{array}$ & $\begin{array}{l}\text { Classification } \\
\text { method }\end{array}$ & $\begin{array}{c}\text { Performance (Training/ } \\
\text { Test) }\end{array}$ \\
\hline $\begin{array}{l}\text { Anna Luisa } \\
\text { Di Stefano } \\
\text { et al. (67) }\end{array}$ & $66 / 78$ & $\begin{array}{l}\text { To characterize } \\
\text { the clinical, } \\
\text { radiological, and } \\
\text { molecular profile } \\
\text { of F3T3 positive } \\
\text { diffuse gliomas }\end{array}$ & $\begin{array}{l}\text { T1WI, CE-T1WI } \\
\text { and FLAIR }\end{array}$ & $\begin{array}{l}\text { ^ITK-SNAP } \\
\text { software }\end{array}$ & $2616 / 25$ & $\begin{array}{l}\text { Cox } \\
\text { proportional } \\
\text { hazards } \\
\text { models (OS) }\end{array}$ & RF(F3T3) & *F3T3: 0.87/0.745(AUC) \\
\hline $\begin{array}{l}\text { Xiaorui Su } \\
\text { et al. (71) }\end{array}$ & $75 / 25$ & $\begin{array}{l}\text { To predict H3 } \\
\text { K27M mutation } \\
\text { status in midline } \\
\text { gliomas. }\end{array}$ & FLAIR & $\begin{array}{l}\text { ^ITK-SNAP } \\
\text { software }\end{array}$ & $99 / 10$ & TPOT & TPOT & $\begin{array}{l}{ }^{\star \star \star} 0.788 \sim 0.867 / 0.60 \sim 0.84 \\
\text { (accuracy) }\end{array}$ \\
\hline $\begin{array}{l}\text { Zev A. } \\
\text { Binder } \\
\text { et al. (59) }\end{array}$ & 260/n.a. & $\begin{array}{l}\text { To investigate the } \\
\text { negative survival } \\
\text { impact of } \\
\text { EGFRA289D/TN }\end{array}$ & $\begin{array}{l}\text { T1WI, CE-T1WI, } \\
\text { T2WI, FLAIR, DTI, } \\
\text { and DSC }\end{array}$ & $\wedge \wedge$ GLISTRboost & $2104 / 299 / 17$ & $\begin{array}{l}\text { SVM/ } \\
\text { radiographic } \\
\text { interpretability }\end{array}$ & n.a. & n.a. \\
\hline $\begin{array}{l}\text { Jingwei } \\
\text { Wei et al. } \\
(50)\end{array}$ & $74 / 31$ & $\begin{array}{l}\text { To predict MGMT } \\
\text { methylation status } \\
\text { in astrocytoma }\end{array}$ & $\begin{array}{l}\text { CE-T1WI, FLAIR } \\
\text { and DWI }\end{array}$ & $\begin{array}{l}\text { ^ITK-SNAP } \\
\text { software }\end{array}$ & $3051 / 13$ & $\begin{array}{l}\text { The minimum } \\
\text { redundancy } \\
\text { maximum } \\
\text { relevance } \\
\text { (mRMR) }\end{array}$ & logistic regression & \#0.925/0.902(AUC) \\
\hline $\begin{array}{l}\text { Yiming Li } \\
\text { et al. (51) }\end{array}$ & $\begin{array}{l}\text { 63/123(32 } \\
\text { internal } \\
\text { and } 91 \\
\text { external) }\end{array}$ & $\begin{array}{l}\text { To predict ATRX } \\
\text { mutation in LGGs }\end{array}$ & $\mathrm{T} 2 \mathrm{WI}$ & $\begin{array}{l}\text { ^MRlcro } \\
\text { software }\end{array}$ & $431 / 9$ & LASSO & SVM & $\begin{array}{l}\# 0.94 / 0.925 \text { (internal) and } \\
0.725 \text { (external)(AUC) }\end{array}$ \\
\hline $\begin{array}{l}\text { Johannes } \\
\text { Haubold } \\
\text { et al. (52) }\end{array}$ & $28 / 14$ & $\begin{array}{l}\text { To predict tumor } \\
\text { grading and } \\
\text { mutational status } \\
\text { of patients with } \\
\text { cerebral gliomas }\end{array}$ & $\begin{array}{l}\text { CE-T1WI, ADC, } \\
\text { and 3D-FLAIR } \\
\text { (SPACE), FET } \\
\text { PET, and SWI, } \\
\text { The water- } \\
\text { content-based M0 } \\
\text { map (MRF M0), } \\
\text { T1FLAIR, DWI }\end{array}$ & $\begin{array}{l}\text { ^^3D Slicer } \\
\text { software }\end{array}$ & $\begin{array}{l}\text { 19284/32 } \\
\text { (1p19q } \\
\text { codeletion), } 64 \\
\text { (IDH1), } 8 \\
\text { (ATRX), 16 } \\
\text { (MGMT) }\end{array}$ & $\begin{array}{l}\text { f score } \\
\text { (ANOVA), } \\
\text { chi-square, } \\
\text { LCSI and } \\
\text { randomized } \\
\text { logistics } \\
\text { regression } \\
\text { (RandLR) }\end{array}$ & RF and SVM & $\begin{array}{l}\text { *WHOI-IV:0.818/n.a.(AUC); } \\
\text { Differentiation of LGG and } \\
\text { HGG:0.85/n.a.(AUC); } \\
\text { 1p19q codeletion: 0.9784/ } \\
\text { n.a.(AUC); IDH1:0.88/ } \\
\text { n.a.(AUC); ATRX:0.851/ } \\
\text { n.a.(AUC); MGMT:0.757/ } \\
\text { n.a.(AUC) }\end{array}$ \\
\hline $\begin{array}{l}\text { Luyuan } \\
\text { Zhang et al. } \\
\text { (57) }\end{array}$ & $96 / 24$ & $\begin{array}{l}\text { To identify the } \\
\text { value of } \mathrm{CIC} \\
\text { mutations in } \\
\text { gliomas }\end{array}$ & $\begin{array}{l}\text { T1WI, T2WI, } \\
\text { FLAIR and CE- } \\
\text { T1WI }\end{array}$ & $\begin{array}{l}\wedge \text { FSL image } \\
\text { viewer }\end{array}$ & $6676 / 11$ & LASSO & logistic regression & ${ }^{\star} 0.985 /$ n.a.(AUC) \\
\hline $\begin{array}{l}\text { Changliang } \\
\text { Su et al. } \\
(53)\end{array}$ & 220/n.a. & $\begin{array}{l}\text { To differentiate } \\
\text { among glioma } \\
\text { subtypes and } \\
\text { predict tumour } \\
\text { proliferation }\end{array}$ & $\begin{array}{l}\text { T2WI fast-echo } \\
\text { images (T2FSE), } \\
\text { T1WI, FLAIR, CE- } \\
\text { T1WI, DWI, PWI } \\
\text { and CBF }\end{array}$ & $\wedge \wedge$ ImageJ & $431 / 25$ & $\begin{array}{l}\text { univariate } \\
\text { analysis }\end{array}$ & logistic regression & \#0.936/n.a.(AUC) \\
\hline $\begin{array}{l}\text { Yiming Li } \\
\text { et al. (76) }\end{array}$ & $69 / 40$ & $\begin{array}{l}\text { To predict PTEN } \\
\text { mutation status in } \\
\text { GBM }\end{array}$ & $\begin{array}{l}\text { T1WI, T2WI and } \\
\text { CE-T1WI }\end{array}$ & $\begin{array}{l}\text { ^MRlcro } \\
\text { software }\end{array}$ & $862 / 6$ & $\begin{array}{l}\text { The minimum } \\
\text { redundancy } \\
\text { maximum } \\
\text { relevance } \\
\text { (mRMR) }\end{array}$ & SVM & \#0.925/0.787(AUC) \\
\hline
\end{tabular}


cross validation not available;

AUC, area under the receiver operating characteristic curve; GBM, glioblastoma; BM, brain metastases; PsP, pseudoprogression; CCC, concordance correlation coefficient; IDH,


selection operator; MGMT, O6-methylguanineDNA-methyltransferase; EGFR, epidermal growth factor receptor; TRC, treatment-related changes; RFE, recursive feature elimination; RF, random forest; SAM, significance analysis of microarrays; SVM, support vector machine; n.a., not available; PCA, principal component analysis;

MRI, magnetic resonance imaging; $m R M R$, minimum redundancy maximum relevance algorithm; MRS, magnetic resonance spectroscopy; DTI, diffusion tensor imaging; DWI, diffusion-

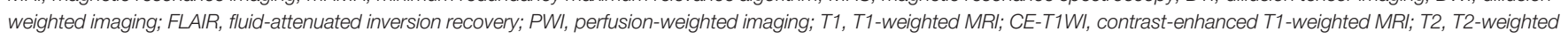
MRI; DSC, dynamic susceptibility contrast; CBV, cerebral blood volume.

outstanding contrast capacity for the detection of brain tissues. Second, MRI has many different sequences respectively sensitive to different physiology parameters, such as blood flow and edema in surroundings, which indicate the tumor's microenvironment. Third, MRI can be implemented throughout the treatment noninvasively and assesses the progression and effect. Besides this anatomical imaging, the multimodal MRI with emerging sequences and technical developments like PET using either amino acid, choline, or fluorodeoxyglucose, as well as fusion $\mathrm{PET} / \mathrm{CT}$ and PET/MRI scanners, provides a mass of functional 
TABLE 2 | Radiomic.

\begin{tabular}{|c|c|c|c|c|c|c|c|c|}
\hline Study & $\begin{array}{l}\text { No. of } \\
\text { patients } \\
\text { involved } \\
\text { (Training/ } \\
\text { Test) }\end{array}$ & General purpose & $\begin{array}{l}\text { CT or } \\
\text { MRI } \\
\text { contrast } \\
\text { (s) }\end{array}$ & $\begin{array}{l}\text { Segmentation } \\
\text { method }\end{array}$ & $\begin{array}{l}\text { Nomber of } \\
\text { features } \\
\text { (extraction/ } \\
\text { selection) }\end{array}$ & $\begin{array}{l}\text { Feature } \\
\text { selection } \\
\text { method }\end{array}$ & $\begin{array}{l}\text { Classification } \\
\text { method }\end{array}$ & $\begin{array}{c}\text { Performance (Training/ } \\
\text { Test) }\end{array}$ \\
\hline $\begin{array}{l}\text { Daesung } \\
\text { Kang et al. } \\
\text { (82) }\end{array}$ & $112 / 42$ & $\begin{array}{l}\text { To identify atypical PCNSL } \\
\text { mimicking GBM }\end{array}$ & $\begin{array}{l}\text { T1WI, } \\
\text { T2WI, } \\
\text { FLAIR, } \\
\text { DWI, CE- } \\
\text { T1WI and } \\
\text { DSC }\end{array}$ & $\begin{array}{l}\wedge \wedge \text { MITK } \\
\text { software }\end{array}$ & $\begin{array}{l}\text { 1618/15 } \\
\text { (ADC), } 40 \\
\text { (CE-T1WI) }\end{array}$ & $\begin{array}{l}\text { RFE(ADC); } \\
\text { relief (CE- } \\
\text { T1W1) }\end{array}$ & $\begin{array}{l}\text { RF(ADC); LDA } \\
(\mathrm{CE}-\mathrm{T} 1 \mathrm{WI})\end{array}$ & $\begin{array}{l}{ }^{\star * \star} 0.983(\mathrm{AUC}) / 0.984 \\
\text { (internal AUC) } 0.944 \\
\text { (external AUC) }\end{array}$ \\
\hline $\begin{array}{l}\text { Guoqing Wu } \\
\text { et al. (83) }\end{array}$ & $67 / 35$ & $\begin{array}{l}\text { To differentiate PCNSL and } \\
\text { GBM and for IDH1 mutation } \\
\text { estimation }\end{array}$ & $\begin{array}{l}\text { T2WI and } \\
\text { CE-T1WI }\end{array}$ & $\wedge \wedge \wedge \mathrm{CNN}$ & $968 / 49$ & $\begin{array}{l}\text { Sparse } \\
\text { representation }\end{array}$ & $\begin{array}{l}\text { Collaborative } \\
\text { sparse } \\
\text { representation }\end{array}$ & $\begin{array}{l}{ }^{* \star} 98.51 \% / 94.51 \% \\
\text { (accuracy) }\end{array}$ \\
\hline $\begin{array}{l}\text { Zenghui Qian } \\
\text { et al. (81) }\end{array}$ & $227 / 185$ & $\begin{array}{l}\text { To differentiate GBM from BM } \\
\text { preoperatively }\end{array}$ & $\begin{array}{l}\text { T1WI, } \\
\text { T2WI and } \\
\text { CE-T1WI }\end{array}$ & $\begin{array}{l}\text { ^MRlcro } \\
\text { software }\end{array}$ & $1303 / 24$ & LASSO & SVM & ${ }^{*} 0.945 / 0.90(A \cup C)$ \\
\hline $\begin{array}{l}\text { Jung Youn } \\
\text { Kim et al. (86) }\end{array}$ & $\begin{array}{l}61 / 57(23 \\
\text { internal } \\
\text { and } 34 \\
\text { external) }\end{array}$ & $\begin{array}{l}\text { To differentiate PsP from early } \\
\text { tumor progression in patients } \\
\text { with GBM }\end{array}$ & $\begin{array}{l}\text { CE-T1WI, } \\
\text { FLAIR, } \\
\text { ADC and } \\
\text { CBV } \\
\text { maps }\end{array}$ & $\begin{array}{l}\wedge \wedge \text { MITK } \\
\text { software }\end{array}$ & $6472 / 12$ & $\begin{array}{l}\text { LASSO } \\
\text { logistic } \\
\text { regression } \\
\text { model }\end{array}$ & $\begin{array}{l}\text { Student's t-test } \\
\text { and the chi- } \\
\text { square test }\end{array}$ & 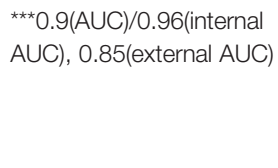 \\
\hline $\begin{array}{l}\text { Katrin Aslan } \\
\text { et al. (91) }\end{array}$ & $\begin{array}{l}\text { 148/ } \\
\text { n.a.(mice) }\end{array}$ & $\begin{array}{l}\text { To predict treatment response } \\
\text { and PSP in ICB-treated mice }\end{array}$ & $\begin{array}{l}\text { T2WI and } \\
\text { CE-T1WI }\end{array}$ & $\begin{array}{l}\text { ^Osirix or } \\
\text { ITKsnap } \\
\text { software }\end{array}$ & $423 / 423$ & / & $\begin{array}{l}\text { Gradient } \\
\text { boosting }\end{array}$ & *82.7\%/n.a. (accuracy) \\
\hline $\begin{array}{l}\text { Nabil } \\
\text { Elshafeey } \\
\text { et al. (84) }\end{array}$ & $98 / 7$ & $\begin{array}{l}\text { To discriminate PsP from } \\
\text { progression in GBM }\end{array}$ & $\begin{array}{l}\text { FLAIR, } \\
\text { T1WI and } \\
\text { CE-T1WI }\end{array}$ & $\begin{array}{l}\wedge \wedge 3 D \text { Slicer } \\
\text { software }\end{array}$ & $620 / 60$ & $\begin{array}{l}\text { Maximum } \\
\text { Relevance } \\
\text { Minimum } \\
\text { Redundancy } \\
\text { (MRMR) }\end{array}$ & SVM & **89\%/n.a.(AUC) \\
\hline $\begin{array}{l}\text { Jinhua Cai } \\
\text { et al. (90) }\end{array}$ & $\begin{array}{l}77 / 72(41 \\
\text { internal } \\
\text { and } 31 \\
\text { external) }\end{array}$ & $\begin{array}{l}\text { To predict the response to } \\
\text { bevacizumab in patients with } \\
\text { brain necrosis after radiotherapy }\end{array}$ & FLAIR & $\begin{array}{l}\text { ^^3D Slicer } \\
\text { software }\end{array}$ & $1301 / 18$ & LASSO & $\begin{array}{l}\text { multivariate } \\
\text { logistic }\end{array}$ & $\begin{array}{l}\# 0.916 / 0.912 \text { (internal) } \\
\text { and 0.827 (external)(AUC) }\end{array}$ \\
\hline $\begin{array}{l}\text { Philipp } \\
\text { Lohmann } \\
\text { et al. (85) }\end{array}$ & $72 / 30$ & $\begin{array}{l}\text { To differentiate PsP in glioma } \\
\text { patients post-chemoradiation }\end{array}$ & FET PET & $\begin{array}{l}\wedge \wedge \wedge \mathrm{TBR}=1.4 \\
1,6,1.8\end{array}$ & $944 / 4$ & RFE & TPOT & ${ }^{\star} 0.74 / 0.74$ (AUC) \\
\hline $\begin{array}{l}\text { Kai Wang } \\
\text { et al. ( } 87)\end{array}$ & $112 / 48$ & $\begin{array}{l}\text { To discriminate tumor } \\
\text { recurrence from radiation } \\
\text { necrosis in glioma }\end{array}$ & $\begin{array}{l}\text { CE-T1WI, } \\
\text { FLAIR, } \\
\text { 18F-FDG } \\
\text { and 11C- } \\
\text { MET PET }\end{array}$ & $\begin{array}{l}\text { ^ITK-SNAP } \\
\text { software }\end{array}$ & $396 / 15$ & LASSO & $\begin{array}{l}\text { Multivariable } \\
\text { logistic } \\
\text { regression } \\
\text { analysis }\end{array}$ & ***0.988/0.914(AUC) \\
\hline $\begin{array}{l}\text { Zi-Qi Pan } \\
\text { et al. (94) }\end{array}$ & $\begin{array}{l}82 / 70(40 \\
\text { internal } \\
\text { and } 30 \\
\text { external) }\end{array}$ & $\begin{array}{l}\text { To predict the response of } \\
\text { individual GBM patients to } \\
\text { radiotherapy }\end{array}$ & $\begin{array}{l}\text { T1WI, } \\
\text { CE-T1WI, } \\
\text { T2WI, } \\
\text { and } \\
\text { FLAIR }\end{array}$ & $\begin{array}{l}\text { ^AGISTR } \\
\text { software }\end{array}$ & $28496 / 8$ & $\begin{array}{l}\text { Boruta } \\
\text { algorithm }\end{array}$ & RF & $\begin{array}{l}{ }^{* * *} 0.764 / 0.758 \text { (external) } \\
(\mathrm{C} \text {-index) }\end{array}$ \\
\hline $\begin{array}{l}\text { Xing Liu et al. } \\
\text { (103) }\end{array}$ & $216 / 84$ & $\begin{array}{l}\text { To predict the PFS in LGGs and } \\
\text { investigate the corresponding } \\
\text { genetic background }\end{array}$ & T2WI & $\begin{array}{l}\text { ^MRlcro } \\
\text { software }\end{array}$ & $431 / 9$ & $\begin{array}{l}\text { Univariate } \\
\text { Cox } \\
\text { regression }\end{array}$ & $\begin{array}{l}\text { LASSO Cox } \\
\text { regression }\end{array}$ & ***0.684/0.823(C-index) \\
\hline $\begin{array}{l}\text { Sara } \\
\text { Dastmalchian } \\
\text { et al. (95) }\end{array}$ & 31/n.a. & $\begin{array}{l}\text { To differentiate between intra- } \\
\text { axial adult brain tumors and to } \\
\text { predict survival in the GBM } \\
\text { cohort }\end{array}$ & $\begin{array}{l}\text { T1WI, } \\
\text { T2WI, } \\
\text { FLAIR } \\
\text { and CE- } \\
\text { T1WI }\end{array}$ & $\begin{array}{l}\wedge \text { Magnetic } \\
\text { resonance } \\
\text { fingerprinting }\end{array}$ & $39 / 20$ & $\begin{array}{l}\text { Spearman's } \\
\text { rank } \\
\text { correlation } \\
\text { coefficient } \\
\text { test }\end{array}$ & $\begin{array}{l}\text { Wilcoxon rank } \\
\text { sum }\end{array}$ & $\begin{array}{l}\text { \#Peripheric white matter } \\
\text { regions in GBM and } \\
\text { LGGs: 0.869/n.a.(AUC), } \\
\text { Solid tumor regions in } \\
\text { LGGs and metastases: } \\
\text { 0.952/n.a. (AUC) }\end{array}$ \\
\hline $\begin{array}{l}\text { Zenghui Qian } \\
\text { et al. (102) }\end{array}$ & $85 / 148$ & $\begin{array}{l}\text { To identify OS in patients with } \\
\text { LGGs }\end{array}$ & $\mathrm{T} 2 \mathrm{WI}$ & $\wedge$ MRlcro & $55 / 6$ & $\begin{array}{l}\text { univariate Cox } \\
\text { regression }\end{array}$ & $\begin{array}{l}\text { multivariate } \\
\text { Cox regression }\end{array}$ & \#0.92/0.70(C-index) \\
\hline $\begin{array}{l}\text { László Papp } \\
\text { et al. (97) }\end{array}$ & $42 / 28$ & To estimate survival for glioma & $\begin{array}{l}\text { 11C-MET } \\
\text { PET }\end{array}$ & $\wedge \wedge$ Hybrid 3D & $112 / 56$ & $\begin{array}{l}\text { Genetic } \\
\text { algorithm and } \\
\text { Nelder-Mead } \\
\text { method }\end{array}$ & $\begin{array}{l}\text { geometric } \\
\text { probability } \\
\text { covering } \\
\text { algorithms }\end{array}$ & $\begin{array}{l}\text { Monte Carlo cross- } \\
\text { validation, n.a./0.9 } \\
\text { (M36IEP AUC) }\end{array}$ \\
\hline
\end{tabular}


TABLE 2 | Continued

\begin{tabular}{|c|c|c|c|c|c|c|c|c|}
\hline Study & $\begin{array}{l}\text { No. of } \\
\text { patients } \\
\text { involved } \\
\text { (Training/ } \\
\text { Test) }\end{array}$ & General purpose & $\begin{array}{l}\text { CT or } \\
\text { MRI } \\
\text { contrast } \\
\text { (s) }\end{array}$ & $\begin{array}{l}\text { Segmentation } \\
\text { method }\end{array}$ & $\begin{array}{l}\text { Nomber of } \\
\text { features } \\
\text { (extraction/ } \\
\text { selection) }\end{array}$ & $\begin{array}{l}\text { Feature } \\
\text { selection } \\
\text { method }\end{array}$ & $\begin{array}{l}\text { Classification } \\
\text { method }\end{array}$ & $\begin{array}{c}\text { Performance (Training/ } \\
\text { Test) }\end{array}$ \\
\hline $\begin{array}{l}\text { Sohi Bae } \\
\text { et al. (96) }\end{array}$ & $163 / 54$ & $\begin{array}{l}\text { To predict survival in patients } \\
\text { with GBM }\end{array}$ & $\begin{array}{l}\text { T1WI, } \\
\text { T2WI, } \\
\text { FLAIR, } \\
\text { 3D CE- } \\
\text { T1WI and } \\
\text { DTI }\end{array}$ & $\begin{array}{l}\wedge \wedge \text { signal } \\
\text { intensity } \\
\text { thresholding, } \\
\text { region growing, } \\
\text { and edge } \\
\text { detection }\end{array}$ & $796 / 18$ & $\begin{array}{l}\text { Random } \\
\text { survival forest }\end{array}$ & $\begin{array}{l}\text { Random } \\
\text { survival forest }\end{array}$ & $\begin{array}{l}{ }^{\star * \star} \text { Overall survival: n.a./ } \\
\text { 0.652, Progression-free } \\
\text { survival: n.a./ 0.590(iAUC) }\end{array}$ \\
\hline $\begin{array}{l}\text { Niha Beig } \\
\text { et al. (98) }\end{array}$ & $\begin{array}{l}83 / 113 \\
\text { (male), } \\
47 / 70 \\
\text { (female) }\end{array}$ & $\begin{array}{l}\text { To develop sexually dimorphic } \\
\text { radiomic risk score (RRS) } \\
\text { models that are prognostic of } \\
\text { OS }\end{array}$ & $\begin{array}{l}\text { CE-T1WI, } \\
\text { T2WI and } \\
\text { FLAIR }\end{array}$ & $\wedge \wedge$ CapTK & $\begin{array}{l}105 / 8 \\
\text { (male), 287/ } \\
6 \text { (female) }\end{array}$ & LASSO & Cox regression & $\begin{array}{l}\# 0.73 / 0.88(C-i n d e x \\
\text { male), } 0.73 / 0.69(C-i n d e x \\
\text { female) }\end{array}$ \\
\hline $\begin{array}{l}\text { Maikel } \\
\text { Verduin et al. } \\
\text { (99) }\end{array}$ & $142 / 46$ & $\begin{array}{l}\text { To established prognostic } \\
\text { clinical features, predict IDH- } \\
\text { mutation, MGMT-methylation } \\
\text { and EGFR amplification develop } \\
\text { a prognostic model for OS in } \\
\text { GBM }\end{array}$ & $\begin{array}{l}\text { CE-T1Wl } \\
\text { and T2Wl }\end{array}$ & $\begin{array}{l}\text { ^Osirix Lite and } \\
\text { MiM software }\end{array}$ & $1197 / 5$ & XGBoost & Cox-regression & ${ }^{\star \star *} 0.72 / 0.73(\mathrm{C}-$-index $)$ \\
\hline $\begin{array}{l}\text { Philipp } \\
\text { Kickingereder } \\
\text { et al. (100) }\end{array}$ & $120 / 61$ & To stratify patients with GBM & $\begin{array}{l}\text { CE-T1WI, } \\
\text { T2WI and } \\
\text { FLAIR }\end{array}$ & $\wedge \wedge I T K-S N A P$ & $1043 / 386$ & $\mathrm{CCC}$ & $\begin{array}{l}\text { Lasso- } \\
\text { penalized Cox } \\
\text { model (Coxnet } \\
\text { algorithm) }\end{array}$ & $\begin{array}{l}{ }^{\star \star *} 0.103 \text { (all layers, OS } \\
\text { IBS); 0.089(all layers, PFS } \\
\text { IBS) }\end{array}$ \\
\hline
\end{tabular}

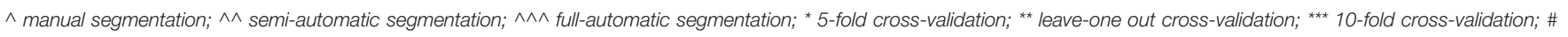
cross validation not available;

AUC, area under the receiver operating characteristic curve; GBM, glioblastoma; BM, brain metastases; PsP, pseudoprogression; CCC, concordance correlation coefficient; IDH,

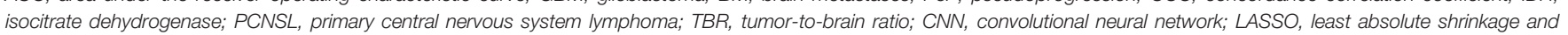


random forest; SAM, significance analysis of microarrays; SVM, support vector machine; n.a., not available; PCA, principal component analysis;

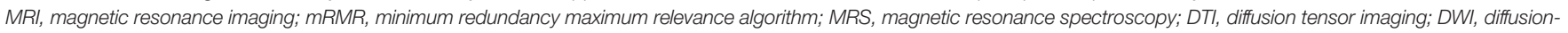

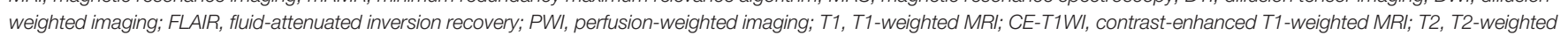
MRI; DSC, dynamic susceptibility contrast; CBV, cerebral blood volume.

neuroradiological information towards tumor penetration boundaries and heterogeneity in brain tumor patients $(9,10)$.

\section{Radiogenomics}

In 2016, WHO published a new guideline on classifying CNS tumors; the molecular markers are especially spotlighted to describe brain tumor entities histology features for the first time, which leads to more precise tumor cataloging (11). Furthermore, target therapies and treatment strategies for malignant brain tumor patients are also predominantly dependent on specific molecular markers, emphasizing the importance of precision oncology. With the advance of big data and bioinformatics, it is possible to detect the correlations between gene expression and radiomics features, which is known as radiogenomics. Radiogenomics is based on a common hypothesis that the dissimilarities in phenotypes of ROIs can be attributed to gene-expression patterns (12). Panth et al. further proved that genetic changes that lead to phenotypic consequences can be reflected in variations of radiomics features (13). The main tasks of radiogenomics are to investigate the correlation between germline genotypic variance and the large clinical post-radiotherapy variability (14), as well as the correlation between specific imaging features and the inherent cellular pathophysiology (15).
Radiogenomics is analogous to the combination of radiology and genomics, but people should be aware that a sole radiomics analysis without biopsy genomics confirmation is not robust enough for definitive assessment of gene expression or other contents in ROIs. On the one hand, radiomics or radiogenomics only reveals the correlation between features and genetic alterations, not the causes. On the other hand, not all of the phenotypic differences are induced only by genetic alteration, but also epigenetic changes and other factors. Thus, they actually incorporate with histopathologic examinations or sequencing, which provides confirmatory information to improve clinical decision making. Radiogenomics holds great potential for an expanding translational technology, mainly due to three characteristics:

First of all, while genomic sequencing usually uses biopsy samples from one representative part of the tumor, the radiomics data is derived from the entire tumor lesion, so the outcome can capture radiomics features on the whole. As a result, radiogenomics supplements genomic sequencing with intratumoral heterogeneity and even intertumoral heterogeneity. Several recent studies have exhibited the role of radiogenomics in identifying regional genetic heterogeneity in malignant tumor with broad genetic diversity that led to treatment resistance such as glioblastoma (GBM) (16-18). 
The following advantage lies in that radiogenomics are easy, rapid, noninvasive, and dynamic, as well as cost-effective. As imaging becomes routine for patients who are suspicious of brain tumor and the estimated error rate of cancer histopathology can be as high as 23\% (19-22), quantitative imaging provides additional information to avoid observer variability and indicates actual biopsy sites. For those who have contraindications of biopsy, radiomics or radiogenomics is expected to serve as a secondary substitution to guide individualized medicine. As far as costs are concerned, radiomics are usually low cost compared to biopsy; it costs around 2000 dollars for a brain biopsy in China, but less than half of that for radiomics. In addition, brain biopsy is an invasive procedure that includes risks like bleeding, seizure, infection, and even paralysis or death for key lesions like basal area and brain stem. Consequently, radiomics outweighs biopsy in costs and risks. Since radiomics or radiogenomics is easy and rapid, they enable the monitoring of the change of gene expression in the tumor's different regions, which may potentially indicate the causes of gene mutation.

Finally, there are single features strongly related to genes, and a cluster of features not significantly correlative to genes, but that have the potential to provide the information with some sort of combination, which has made progress in predicting cancer immunotherapy. By combining CT radiomics features and genomic data based on CD8B, Sun et al. developed a novel radiomics-based biomarker to predict CD8 cell count and clinical outcomes of patients' response to anti-PD-1 or antiPD-L1, when validated by further prospective randomized trials (23). In an AI-based radiomics study by Trebeschi et al., the biomarker mainly regarding tumor proliferation could predict anti-PD-1 therapy response with an AUC of up to 0.76 for both advanced melanoma and non-small-cell lung cancer (NSCLC) patients (24). It is also promising to see more robust radiomicsbased biomarkers on targeted therapy in the future, such as antiangiogenic treatment with bevacizumab (25). To improve the resolution and confidence of features' subsets related to gene modification or expression, big data from multiple centers should be collected and integrated.

\section{PITUITARY TUMOR}

Pituitary adenomas (PAs) are among the leading types of brain tumors, and the foremost frequent lesion in sellar area. Usually, the hormone hypersecretion is assessed by immunocytochemical or hormone assays to distinguish secretory tumor from non-secretory ones. And the evaluation of tumor mass, such as accurate location and volume, is based on diagnostic imaging and visual field examination. Accurate clinical diagnosis derived from tumor characteristics helps individualized treatment. Radiomics will likely never replace histopathology or hormonal diagnosis for adenomas. However, separately, AI algorithms may replace the work performed by pathologists in interpreting microscopic analyses. Recent progress in pituitary tumors, gliomas, and brain metastases are arranged and summarized in Tables 1, 2.

\section{Evaluation of Aggression}

$\mathrm{Ki}-67$ is only expressed in the nucleus of proliferating cells and the Ki-67 labeling index is considered to be an ideal indicator for detecting cell proliferation activity. PAs may exhibit clinically invasive or aggressive behavior, accompanied by postoperative recurrence and resistance to multidimensional therapy, which is usually evaluated by $\mathrm{Ki}-67$ labeling index through immunohistochemistry. Ugga et al. collected 89 patients with available Ki-67 data and performed k-nearest neighbors (k-NN) to build a radiomics classifier using 12/1128 quantitative radiomics features to evaluate the Ki-67 labeling index based on preoperative T2WI MRI, which is effective and accurate (accuracy 91.67\%) (63).

Knosp grade describes the degree of PA invasion to bilateral cavernous sinuses (CS). Niu et al. predicted CS invasion in 194 PA patients (training cohort: 97; test cohort: 97) graded 2-3 with Knosp pre-operatively by radiomics approaches deriving from contrast-enhanced T1 (CE-T1) and T2WI MRI (64). They applied LASSO to select three important features and establish a classifier using support vector machine (SVM), which yielded decent AUC values (training cohort: 0.852, test cohorts: 0.826).

\section{Grading}

The regulation of adenohypophyseal cell differentiation and hormone secretion are operated by a series of transcription factors, including Tpit, Pit-1, and SF-1. Peng et al. involved 235 patients with pituitary adenoma (PA), and 18 quantitative imaging features were verified as significant to train SVM, k-NN, and Naïve Bayes (NBs) models to classify the transcription factor types of PAs. Among the three models, the SVM model showed the best performance (AUC 0.9549) whereas the K-NN (AUC 0.9266) and NBs (AUC 0.9324) models displayed lower performance and they found better performance in T2weighted than Tl-weighted and CE-T1 (65).

Zhang et al. worked on differential diagnosis of nonfunctioning pituitary adenomas (NFPAs) subtypes from other subtypes preoperatively (66). They enrolled 75 patients as the training cohort and 37 patients as the test cohort, and derived complete T1-WI and CE-T1 MRI. The top three T1-WI imaging features, rather than CE-T1 imaging features, were ultimately selected using mRMR to fit a Radial Basis Function (RBF)-SVM predictive signature. A nomogram incorporated clinical characteristics and the radiomics signature corresponding to the best predictive model for individual prediction. Finally, the calibration of the nomogram was presented with a concordance index (CI) (training cohort: 0.854, test cohort: 0.857 ).

\section{Prediction of Treatment Response}

Prolactinoma is the most common secretory PA, with prime treatment being dopamine agonists (DA) such as bromocriptine. To assess prolactinoma patients' response to DA before initiating the treatment plan, Park et al. investigated a total of 177 prolactinoma patients' coronal T2-weighed MRIs and set up a radiomics predictor with an AUC of 0.81 in both training and test cohorts (26). 
Acromegaly is a severe complication that leads to poor prognosis most frequently caused by somatotroph PAs that secrete excessive growth hormone (GH). For those who are not suitable for surgery or have severe symptoms, somatostatin receptor ligand (SRL) treatment is usually applied to reduce the volume of mass preoperatively (67-69). To predict the treatment response of SRL ahead of surgical resection, radiomics features from MRI are selected to predict the histological granulation pattern. Park et al. set up a radiomics prediction model based on $69 \mathrm{GH}$-secreting PA patients and the model showed an AUC of $73.7 \%$ (70).Fan et al. proposed a radiomics prediction model of invasive functional pituitary adenoma (IFPA) working on the treatment responses before surgery (71). The prediction model was incorporated with a radiomics signature based on seven selected features derived from MRI and Knosp grade of each IFPA patient. The discrimination abilities and calibration of this yielded good performance, with AUCs (training cohort: 0.832, test cohort: 0.811 ).

\section{Prediction of Recurrence}

Early progression/recurrence $(\mathrm{P} / \mathrm{R})$ is a poor prognostic factor of macro NFPAs that is reported in $25-55 \%$ patients after surgical resection (72-75). Zhang et al. established a SVM radiomics model based on three selected features from 50 patients' 214 preoperative and postoperative follow-ups MRI features extracted from CE-T1 and T2WI yielded an overall accuracy of $82 \%$ and AUC of 0.78 discriminating P/R NFPAs from non-P/R ones using the original mask tumor ROI (27). They also calculated SVM scores for each patient and found that higher scores may correlate with shorter PFS. Regarding SVM score for differentiation of $\mathrm{P} / \mathrm{R}$, the optimal cut-off value was calculated which means patients with SVM scores higher than 0.537 tended to exhibit shorter PSF and the corresponding AUC (0.87) were obtained.

Machado et al. applied 3D CE-T1 MRI of patients preoperatively and segmented two and three-dimensional regions. They evaluated the 255 extracted radiomics features of 27 patients with NFPA and selected six features for twodimensional machine learning radiomics models and 13 for three-dimensional models (76). The results showed 3D-feature based models have superior discrimination ability to classify NFPAs recurrent and stable lesions than 2D-feature based models, with their accuracies of up to $96.3 \%$ compared to accuracies of $92.6 \%$ for models solely based on $2 \mathrm{D}$ features.

\section{GLIOMAS}

Gliomas account for the first leading primary brain and other CNS tumor in adults (25.1\%) (77), making up approximately $80.8 \%$ among primary malignant brain and other CNS tumors with certain diagnoses (11).As the majority of gliomas $(57.7 \%)$, GBM accounts for the foremost and lethal primary malignant brain tumor in neurosurgery, whose overall incidence rate is estimated $0.0032 \%$ in American adults (78). Though multimodal treatment protocols, including maximal safe surgical resection and adjuvant radiation therapy with concurrent chemotherapy mainly temozolomide (TMZ), are standardly given to GBM patients, they still suffer a crushingly adverse prognosis with 14.6 months of median OS (79).

\section{Evaluation of Mutation Status}

Isocitrate dehydrogenase (IDH) mutations are recognized as a good prognostic factor in early clinical intervention and can be integrated into routine clinical practice such as pathological examination via radiomics analysis, immunohistochemistry, flow cytometry, standard PCR, and/or sequencing techniques (80). All IDH-mutant diffuse astrocytic tumors are classified as a single type of tumor (astrocytoma, IDH mutation, grade 2/3/4) and all GBM only included IDH wild type tumors in the 2021 WHO CNS 5. The $1 \mathrm{p} 19 \mathrm{q}$ co-deleted tumors are exclusively oligodendrogliomas. And most oligodendrogliomas with 1p/ $19 \mathrm{q}$ co-deleted, which indicates poor prognosis, are accompanied by IDH1 and IDH2 mutation. In 2016 WHO CNS 4, the guideline of gliomas classification incorporated five molecular subtypes of diffuse gliomas based on IDH mutation and $1 \mathrm{p} / 19 \mathrm{q}$ codeletion status.

Lu et al. built a multilevel quantitative imaging model based on CE-T1 image, T2 FLAIR, T2WI, DWI, and ADC to recognize IDH and $1 \mathrm{p} / 19 \mathrm{q}$ genotypes of glioma and further classification of five molecular types (33). The training cohort involved 214 patients and an additional independent cohort involved 70 patients for external test. The IDH and $1 \mathrm{p} / 19 \mathrm{q}$ classifier using SVM models was established in the training cohort, yielding areas under receiver operating characteristic (ROC) curves ranging from 0.922 to 0.975 , and accuracies ranging from $87.7 \%$ to $96.1 \%$. Correspondingly in the test cohort it showed accuracies between $80.0 \%$ and $91.7 \%$. On classifying five molecular subtypes, the trained classifier with the MR radiomics phenotypes as sole source yielded an accuracy of $81.8 \%$, which further reached a higher accuracy of $89.2 \%$ in the existence of histology diagnosis. Gutsche et al. implemented FET PET to enhance the diagnostic performance of their radiomics features on IDH genotype identification (34). The repeatability of the features was evaluated by calculating the intraclass correlation coefficient (ICC) and 297 features with robust discrimination ability were finally selected.

Deep convolutional neural networks (CNNs) and radiomics share the same procedure but have separate characteristics regarding radiological evaluation on IDH genotypes. Choi et al. reviewed 1166 preoperative CE-T1, T2, and FLAIR neuroimaging of gliomas grading II-IV derived from three centers and developed a CNN-based fully automated model hybridizing conventional MRI that integrated 2D tumor signal intensity and quantitative radiological features from 3D tumor shape and location, which was reproducible and generalizable for noninvasive characterization of IDH status in gliomas (35). Based on CE-T1, T2WI, and FLAIR from 1166 patients with gliomas (training cohort:727; internal test cohort: 129; external test cohort: 310), 20 out of 24 extracted features were selected and the classifier reached an AUC of $0.96,0.94$, and 0.86 
respectively for training cohort, internal validation cohort, and external validation cohort.

The DNA-repairing enzyme O-6-methylguanine-DNA methyltransferase (MGMT) restores cytotoxic lesions in DNA caused by temozolomide chemotherapy, thus leading to drug resistance. Methylation epigenetically silenced MGMT has a connection with a better treatment response and a better prognosis than the unmethylated promoter (81). Based on a group of 105 patients with grade II-IV astrocytoma, Wei et al. established a radiomics model for MGMT promoter methylation prediction with supreme power (AUC: training cohort: 0.925, test cohort: 0.902), which successfully bisected the group into high-risk and low-risk subgroups for OS followed by temozolomide chemotherapy (39). ATRX mutation is another good prognostic factor that usually appears in LGGs accompanied by IDH mutation. Li et al. included 95 patients with LGGs and built a radiomics predictor of ATRX alterations, which was subsequently validated in an external cohort of 91 patients with good performance (AUC: training cohort: 0.94, internal test cohort: 0.925 and external test cohort: 0.725) (40).

Haubold et al. assessed the potential of multimodal imaging and radiomics algorithms to predict the grading and common mutations including MGMT of 42 patients with suspicious primary brain tumor (41). They applied 18F-FET PET along with MR Fingerprinting and extracted 19284 features from each patient, which were further divided into 32 for $1 \mathrm{p} 19 \mathrm{q}$ codeletion, 64 for IDH1, 8 for ATRX, and 16 for MGMT. And through 5-fold cross-validation the AUCs in predicting the mutation were respectively assessed, with $1 \mathrm{p} 19 \mathrm{q}$ for $97.8 \%$, IDH1 for $88.7 \%$, ATRX for $85.1 \%$, and MGMT for $75.7 \%$. The 2016 WHO grading model yielded an AUC of $81.8 \%$ while AUC of discriminating LGG from HGG was $85.2 \%$. Su et al. further investigated grading along with proliferation levels in 220 patients with various grades of gliomas (43). When combining radiomics features of multicontrast MRI (T2WI fast-echo images (T2FSE), T1WI, FLAIR, CE-T1WI, DWI, ADC, PWI and CBF), the models displayed the highest AUC (0.911 for LGGs and HGGs, 0.896 for grades II-III, 0.997 for grades II-IV, 0.881 for grades III-IV, and 0.936 for levels of Ki-67 labeling index).

It has been reported that $C I C$ mutation promotes glioma cell proliferation, differentiation, and aggression and results in a poor outcome (82-84). However, Zhang et al. found that patients with LGGs (IDH mutation) or oligodendroglioma (IDH mutation and $1 \mathrm{p} / 19 \mathrm{q}$ codeletion) combined with CIC mutations may have better prognosis (42). As shown in MRI, LGGs (IDH mutation) with CIC mutation illustrate visually less malignant manifestations, such as fairer necrosis and more homogeneity among the tumor volume. They further developed a radiomics model to predict the $C I C$ alterations based on 11 features derived from 120 patients with LGGs (AUC: 0.985).

Epidermal growth factor receptor (EGFR) variants are reported in $57 \%$ of GBM specimens. Among these, a deletion from exons 2-7, EGFRvIII is the most frequent EGFR variant, and extracellular domain (ECD) missense mutations like A289D/T/V, R108G/K, and G598V are the most frequent EGFR deletion comprising $10 \%-15 \%$ of transcription products while the deletion was found to co-occur with amplification (85). $\mathrm{EGFR}^{\mathrm{A} 289 \mathrm{~V}}$ mutation has the most negative survival impact, which was reinforced by Binder's study involving 260 patients with de novo GBM (38). To investigate the negative prognostic effect of $\mathrm{EGFR}^{\mathrm{A} 289 \mathrm{D} / \mathrm{T} / \mathrm{V}}$, Binder et al. firstly did quantitative imaging analysis comprising six different MRI modalities and extracted 2104 quantitative imaging phenomic features which were further reduced to a more manageable set of 299 using a multivariate classification framework (86). To promote radiographic interpretability, an experienced neuroradiologist further filtered these features into 17. The MRI signatures based on selected features presented a picture of decreased T1 signal but higher CE-T1 signal, higher T2 values, higher peak height $(\mathrm{PH})$ values, and relative cerebral blood volume (rCBV) in $\mathrm{EGFR}^{\mathrm{A} 289 \mathrm{D} / \mathrm{T} / \mathrm{V}}$ mutant tumors region, indicating higher water content, hyperproliferation, and increased invasion in tumor region with $\mathrm{EGFR}^{\mathrm{A} 289 \mathrm{~V}}$. The peritumoral edema region presented reduced fractional anisotropy (FA) generated by Diffusion Tensor Imaging (DTI) for cases with $\mathrm{EGFR}^{\mathrm{A} 289 \mathrm{D} / \mathrm{T} / \mathrm{V}}$ mutations, suggesting decreased tissue organization and homogeneity. Taking MRI signature and following modified cell lines in vivo, they demonstrated higher proliferation, increased aggressiveness, and shorter OS in EGFR ${ }^{\mathrm{A289D} / \mathrm{T} / \mathrm{V}}$. To explore the mechanism in vivo, they inhibited two main signaling pathways of EGFR, RAS/RAK/ERK and PIK3CA/AKT, which revealed that $\mathrm{A} 289 \mathrm{~V}$-induced EGFR activation mediates phosphorylated ERK and augments MMP1 expression which cause hyperproliferation and invasion. Finally, mAb806 targeting therapy was examined in $\mathrm{EGFR}^{\mathrm{A} 289 \mathrm{~V}}$ mice models and was proven to be a potential therapeutic option as the mAb806 antibody reduced the tumor burden, inhabited tumor growth, and improved animal survival.

Glioma cells connect their microenvironment in a two-way street, mainly through cytokines and matrix proteins. POSTN is a secretory extracellular matrix protein made up of gliomas cells. Previous studies showed POSTN plays a role in neovascularization, endothelial junction formation decrease, stem cell maintenance, and macrophage recruitment $(87,88)$. Subsequent studies revealed POSTN in glioma grade, recurrence, and resistance to bevacizumab monoclonal antibody against VEGF-A (89, 90). Zinn et al. found GBM patients with different POSTN expression levels in association with distinct imaging features, which can be utilized in radiomics for prediction (32). They extracted 2480 radiomics features respectively in GBM patients and GSC-derived orthotopic tumors mice and selected 48 and 17 features respectively to build two classifiers (GBM AUC: 76.56\%; mice, AUC: 92.26\%).

F3T3 is a novel fusion proto-oncogene incorporating FGFR3TACC3 found in approximately $3 \%$ of gliomas that functions as an important part in the activation of oxidative phosphorylation and mitochondrial metabolism. Though the foremost energy metabolism pathway of tumor is anaerobic glycolysis, GBM with F3T3 mutation depends on noncanonical mitochondrial pathway. Thus, F3T3 may serve as a potential target for targeting therapies such as mitochondrial inhibitors (91). Stefano et al. showed that, in the midst of IDH-WT tumors, 
F3T3-positive gliomas exhibit distinct molecular, radiological, and clinical features and possess a more optimistic clinical outcome independent of their grading. Their radiomics data composed 66 patients as training cohort and 78 patients from another institution as test cohort and identified F3T3-positive patients with good accuracy. They successfully built a classifier towards F3T3 mutation status (AUC: 0.87(training)/0.745(test)) and a model composing clinical, genetic, and radiomics profile to estimate the F3T3-positive patients' OS as presenting the best concordance (C-index: 0.81). They further implemented multiple optimization techniques (SCCAN) to inspect the tropism of F3T3 gliomas for specific intracranial ROIs and finally located cortical and subcortical regions, especially insula and temporal lobe (36).

H3 K27M mutant occurs within the histone-3 gene (H3F3A) wherein an amino acid recurrently converts from lysine to methionine in the site 27, and H3 K27M-positive diffuse midline glioma is listed separately graded as IV in $2016 \mathrm{WHO}$ classification (92). According to a report, H3 K27M-positive gliomas in thalamus area tend to result in a shorter median OS in pediatric patients than in H3 K27M-WT ones (93). Furthermore, there have been several epigenetic-targeted treatments towards $\mathrm{H} 3 \mathrm{~K} 27 \mathrm{M}$ and an immunological study provided evidence for immunotherapeutic approaches like mutation-specific vaccines targeting H3K27M (94). Su et al. carried out a retrospective study on automated classification of H3 K27M genotypes. The Treebased Pipeline Optimization Tool (TPOT), a method that automatically conducts feature and model selection procedure, along with pipeline optimization, was highlighted. The study included $40 \mathrm{H} 3 \mathrm{~K} 27 \mathrm{M}$-positive patients and $60 \mathrm{WT}$, of whom $75 \%$ were randomly grouped into the training cohort while $25 \%$ into test cohort. After extracting 99 features from FLAIR, TPOT finally refined 10 more manageable radiomics features and generated ten prediction models. The optimal model is generated through comparison of accuracy metrics. The model exhibiting the best performance in the test cohort yielded the highest average precision of 0.911 and AUC of 0.903, while validation in an independent validation dataset observed an average precision of 0.855 and an AUC of 0.85 (37).

Monitoring the core signaling pathway of GBM may reveal the tumor evolution, allow early clinical intervention, and enhance patients' management (95). Park et al. built a radiogenomic classifier based on patients with IDH-WT GBM certified by next-generation sequencing (NGS), which noninvasively predicts retinoblastoma 1, p53, and Receptor tyrosine kinase (RTK) core signaling pathways (31). In this study, 85 patients were classified into the training cohorts in total and 35 into test cohorts, and their T1WI, T2WI, DWI, FLAIR, CE-T1WI, and perfusion MRI-like dynamic susceptibility contrast (DSC) were acquired for radiomics analysis. For each core signaling pathway, 71, 17, and 35 features passed extraction, and finally the top 5 features were selected respectively. Three models were evaluated, presented as AUC (RTK, training cohort: 0.87 , test cohort: 0.88; p53, training cohort: 0.80 , test cohort: 0.76 ; retinoblastoma, training cohort: 0.84, test cohort: 0.81). PTEN is a tumor suppressor gene participating in both ATK and RTK signaling pathways and the deficiency of PTEN is considered to be the main feature of GBM $(96,97)$. In addition to relying on sequencing and immunohistochemistry to detect PTEN alterations, Li et al. established a noninvasive radiomics method with good performance in guiding targeted therapy (AUC: training cohort: 0.925 , test cohort: 0.787$)(44)$.

\section{Differential Diagnosis}

The radiological features of gliomas usually lack specificity, involving spherical well-encapsulated shape with ring enhancement indicating tumor angiogenesis and prominent peritumoral edema. The lesions are mostly multiple and are usually located at watershed or grey-white junction with white matter fiber bundles erosion. Further, the radiological features between malignant gliomas and lymphomas are analogous and there is also similarity in abscesses, infections, demyelinating diseases, and vascular lesions. The radiological features are also likely to be interfered with by hemorrhage, melanin, and paramagnetic ions.

Brain metastases (BMs) take up the second most common type of malignant brain neoplasms in adults preceded by GBM $(98,99)$. Early diagnosis is the key to appropriate therapies since the strategies for these two tumors are distinct with different local control rates and intervention prognosis: the prior treatment for GBM is maximum-safe surgery resection, following adjuvant radiotherapy and chemotherapy (100), while regarding BM the more effective and less invasive treatment is stereotactic radiosurgery (101). Qian et al. assessed high-dimensional radiomics features from $\mathrm{T} 1-\mathrm{WI}, \mathrm{T} 2-\mathrm{WI}$, and $\mathrm{CE}-\mathrm{T} 1$ to distinguish GBM from solitary BM (47). In the retrospective study, patient's population, including 242 GBM and 170 solitary $\mathrm{BM}$, was randomly grouped (training cohort: 227 , test cohorts: 185). An amount of 1303 radiomics features passed extraction, which were then refined by twelve feature selection methods. Thirteen classifiers were generated and all yielded excellent predictive efficacy with $\mathrm{AUC} \geq 0.95$ in the training cohort. Through ROC curve analysis they found out that the combination of SVM and LASSO classifiers had the best prediction value in the test cohort (AUC: 0.90).

Primary central nervous system lymphoma (PCNSL) shares radiological similarities with GBM when solely using ADC parameter, due to some overlaps in ADC values. Kang et al. evaluated the feasibility of a radiomics model for the differentiation of atypical PCNSL and GBM based on ADC (45). The patient population in the training cohort contained 112 patients, while the population in the test cohort involved 42 patients for internal and 42 for external validation sets. They combined 12 feature selection methods with 8 classification methods using 5 50 selected features and optimized 8 ADC radiomics models. The prediction performance and stability were subsequently measured by each AUC and relative standard deviation (RSD) of each model. As a result, the ADC model combining RFE feature selection with RF classification yielded the highest diagnostic value with an AUC of 0.983 in the training cohort. The ADC model showed robustness exceling 
expert readers and was further assessed respectively in the internal validation cohort (AUC 0.984) and external validation cohort (AUC 0.944) to promote generalizability.

To standardize the procedure and improve efficacy, Wu et al. generated a novel radiomics system utilizing feature extraction and selection methods and classification framework based on dictionary learning and sparse representation (46). Simply using T2WI and CE-T1, they tested the technical feasibility of the system using 49 selected radiomics features out of 968 features extracted from 102 patients with PCNSL or GBM (training: test=67:35). The sparse representation radiomics system had superior PCNSL and GBM differentiation performance (training cohort: $98.51 \%$ accuracy, test cohort: $94.51 \%$ accuracy). Furthermore, the IDH1 prediction performance of the novel system exceeded traditional methods based on calculation by $11 \%$.

\section{Prediction of Treatment Effect and Recurrence}

Tumor recurrence in early posttreatment stage is commonly reported in HGGs. Assessing posttreatment MRI changes according to RANO standard within 0-72 hours is a common and effective method to evaluate the degree of surgery. Pseudoprogression (PsP) is a diagnostic dilemma presented as expanded and/or new regions of edema and enhancement, especially within the 2-5 months from the initiation of adjunctive therapies, which mimics tumor recurrence and radiation necrosis. The mechanism of PsP may be attributed to three factors: (1) non-tumor tissue chemoradiation damage, e.g., hemorrhage, ischemia, aseptic inflammation, edema and necrosis; (2) blood-brain barrier breakdown; or (3) other factors, e.g., signal artefacts from metal implants.

A recent retrospective radiomics study comprising 76 patients of histopathology-proved progressive disease (PD) and 22 of PsP from three centers by Elshafeey et al. provided evidence on perfusion MRI on accurately discriminating PD and PsP. Its reported model based solely on Ktrans maps had matching diagnostic value with the $\mathrm{rCBV}$ model in discriminating between PsP and PD. The final prediction model combining Ktrans with rCBV maps generated by SVM used the top 60 radiomics features ranking with MRMR, which achieved an accuracy of $90.82 \%$ and an AUC of $89.10 \%$ in discriminating between PsP and PD. Subsequent validation also showed statistical significance by LOOCV (AUC 89\%) (50). Based on dynamic FET PET radiomics, Lohmann et al. aimed at establishing a reliable diagnostic test for differentiating PsP from tumor progression in gliomas patients (52). In the tumor segmentation process, data augmentation was implemented to increase the number of datasets from 34 patients to 102 . The radiomics model was automatically generated using TPOT based on random forest classification, with an AUC of 0.74 in both training and test cohorts.

Kim et al. investigated the feasibility of multiparametric MRI radiomics incorporating diffusion and perfusion to identify tumor recurrence within 3 months following standard therapy
(48). They developed and validated a radiomics model comprising CE-T1WI, FLAIR, ADC, and CBV maps using 61 patients as training cohort and 23 patients as validation cohort. Initially 6472 features were extracted and then 12 significant radiomics features passed selection using LASSO to construct the integrated model. And the model presented best diagnostic performance (AUC, 0.90) over any single imaging technique or parameter model. The internal validation (AUC, 0.96) and external validation (AUC, 0.85) cohorts strengthened the outcome.

Towards differentiating tumor recurrence from radiation necrosis, Wang et al. carried out a radiomics study involving 112 patients as training cohort and 48 patients as test cohort. The multidimensional quantitative model integrated clinical information (patients' individual features and gliomas grade) and radiomics information (MRI techniques (T1WI, T2WI, CET1WI and FLAIR) and PET images using both 18F-FDG and $11 \mathrm{C}-\mathrm{MET}$ ), while the radiomics model only included radiomics information. Fifteen textural features were selected from the images for the construction of radiomics model and integrated model. And the integrated model showed significant superiority over radiomics model (both training and test cohorts: $\mathrm{p}<0.001$ ) and was proved to be accurate and effective in the prediction of differentiating postoperative tumor recurrence from radiation necrosis (training cohort: AUC 0.988, test cohort: AUC 0.914) (53).

Brain necrosis after radiotherapy is a common complication in approximately $3 \%-24 \%$ of patients (102), mostly with primary or metastatic cancer of the head, neck, and CNS. Bevacizumab has shown its potential in symptomatic relief and radiographic response compared with general corticosteroid therapy in randomized study (103), however, some patients are unable to gain benefit or even worsen. To predict the treatment effect of bevacizumab in brain necrosis patients, Cai et al. developed a radiomics model based on a total of 149 patients including 42 as an external validation cohort, which yielded an AUC of 0.916 in the training cohort and 0.912 and 0.827 in the validation cohorts (51).

Immune checkpoint inhibitors (ICI) hold great promise for GBM treatment, however the suppressive microenvironment of GBM characterized by poor antigen presentation and low T-cell activation and infiltration limits the ICI application. Aslan et al. investigated mechanisms of resistance to ICIs blocking PD-1 and CTLA-4 and acquired immune heterogeneity in the allogeneic intracranial inoculated mice with Gl261 tumor cells (49). To determine the response of ICI in mice post inoculation and identity PsP, they built a radiomics signature based on CE-T1WI and T2-WI. From 101 mice inoculated with Gl261 tumor cell before and during ICI treatment, they extracted 423 features and built a gradient boosting classifier containing all 423 z-score-normalized radiomics features with an accuracy of $82.7 \%$. Subsequent in-vivo and ex-vivo experiments proofed that $\mathrm{PD}-\mathrm{L} 1 / \mathrm{PD}-1 / \mathrm{CD} 80$ axis plays an important role in ICI resistance induced by CD4 $\mathrm{T}$ cell suppression, tumor-associated macrophages, and Treg extension in the microenvironment of GBM. 


\section{Predicting Patient's OS and Complications}

According to a large-scale randomized trial, the median survival time of GBM is 14-15 months, which can be prolonged by adjuvant temozolomide with radiotherapy (104). However, the current radiotherapy plans ignore the biological heterogeneity of individuals and use the same dose, resulting in significant difference in patients' OS (105). Radiomics and radiogenomics can provide an imaging biomarker on predicting the individual radiotherapeutic response, which helps to adjust the dose and make a personalized treatment plan. By combining the clinical risk factors and radiomics signature which was built with 152 patients with GBM to predict the radiotherapeutic response, Pan et al. developed a nomogram to predict the OS, with C-indexes up to 0.764 and 0.758 respectively in the training cohort and external validation cohort (54).

The study by Dastmalchian et al., including 31 patients with GBM, LGGs, and metastases and 20 top selected features, proved that the radiomics approach has robust potentiality to differentiate between these tumors and to predict OS of GBM (56). They found a significant difference between patients with different selected features such as T1/T2 entropy and secondary features like high-gray run emphasis $(\mathrm{p}<0.05)$. And the cut-off values dichotomizing the GBM patients' median survival were calculated by grading these features. For example, lower entropy values in solid tumor regions (p: 0.034) in T2 maps correlate with longer survival of 11 months and 6.7 months for those below the cut-off value, and higher entropy values in peritumoral white matter regions (p: 0.009) in T1 maps correlate with longer survival of 18 months and 6.8 months for those below the cutoff value.

Since the mutation of IDH1-R132H and MGMT in GBM patients is strongly associated with the OS and PFS, Bae integrated radiomics with clinical and genetic profiles and built several models to predict the prognosis of 217 GBM patients (training: test=3:1) (59). From 796 features derived in T1WI, T2WI, FLAIR, postcontrast 3D T1WI, and DTI, they selected 18 significant features and trained multilayers RSF models. Except for the integrated model, the model containing only radiomics features was the most significant with successful validation in the test cohort (OS: iAUC 0.652, PFS: iAUC 0.590).

Papp et al. evaluated the prediction value on dichotomized OS using an integrated model comprising 56 features including 11CMET PET radiomics characteristics in vivo, histopathological characteristics ex vivo, along with patients' individual information to predict survival in glioma patients without treatment (58). The cut-off value determines 36 months as the survival prediction threshold and the prediction weight for each model was assessed in training cohorts and the validation cohorts. When it came to validation, they introduced the Monte Carlo cross-validation (MCCV) different from k-fold validation in that the sample may appear multiple times in the same set (training set/test set). The MCCV proved the highest AUC for the integrated model as 0.9 , following the patient-based and histopathology-based models.

It has been reported that in GBM patients, females exhibit longer OS compared to males, which may be associated with hormonal, metabolic, and immune variances. Based on the discovery, Beig et al. developed sexually dimorphic radiomics risk score (RRS) models to predict patients' OS. The OS prediction model combines age molecular features, extent of resection, and RRS, showing good performance in both male and female cohorts [0.73/0.88(C-index, male), 0.73/0.69(C-index, female)]. By further analyzing radiogenomics associations between MRI-based phenotypes and transcriptomic data correspondingly, they found that RRS is associated with a series of biological activities including angiogenesis, apoptosis, cell differentiation, cell proliferation, and cell adhesion (60).

Verduin et al. involved the training $(\mathrm{n}=142)$ and validation cohort $(n=46)$ to establish a combined model for prognosis of OS in IDH-WT GBM patients based on quantitative radiological features, qualitative Visually Accessible Rembrandt Images (VASARI) features, and clinical information. The accuracy and reproducibility of the combined model was analyzed using Harrell's C-index (training cohort: 0.72, validation cohort: $0.73)$. They additionally developed a prediction model towards molecular mutation status comprising IDH, MGMT methylation, and EGFR amplification in 95 patients for the training cohort and 38 patients for the validation cohort. In this model, 5 VASARI and 5 radiomics features mainly selected from T2WI were considered to be most prognostically relevant, with performance towards MGMT methylation (AUC: 0.667) and EGFR amplification (AUC: 0.707 ) yielding significance in external validation cohorts (61).

A radiomics study on PFS and OS stratification by Kickingereder et al. included $181 \mathrm{GBM}$ patients available of imaging information (CE-T1, FLAIR, and T2WI), DNA methylation profiling (MGMT methylation status and global DNA methylation pattern), treatment (surgery, TMZ chemotherapy and/or radiation), and patients' individual information (62). In the prognostic analysis, a total of 386 features were selected independently in a test-retest MRI cohort. Subsequently, 8 of these were further used to construct a radiomics signature using sole radiomics information. When using only epigenetic and clinical information, the prediction error for PFS (29\%) and 37\% for OS (27\%) is not appreciable, which were reduced by $36 \%$ for a model after integrating radiomics signature. The radiomics signature showed significance beyond models using other information $(\mathrm{P} \leq 0.01)$.

The epilepsy complicated by LGGs is mainly attributed to compression and stimulation of the brain tumors that cause the degeneration and gliosis of the brain cells around the tumors which constitute the epileptic foci complex. Wang Y aimed at predicting epilepsy types to guide more targeted antiepileptic therapy in a retrospective study. A novel radiomics nomogram was developed with 4 selected discriminative MRI features regarding location and molecular background in 205 LGG patients, which displayed excellent quantitative clinical prediction performance (AUC: 0.863) (106). Qian et al. suggested a radiomics risk score to alternatively identify the OS in LGGs. When combined with independent clinical prognostic parameters such as WHO grade, age at diagnosis, and seizure, the nomogram based on the risk score exhibited high prognostic accuracy (C-index: training cohort: 0.92 , 
test cohort: 0.70) (57). They subsequently implemented radiogenomic analysis of high-risk positively associated genes, further revealing the underlying correlated biological processes including hypoxia, angiogenesis, and apoptosis. For the prediction of PFS, Liu et al. worked out a practical nomogram incorporating clinicopathologic factors and a radiomics signature based on 300 patients with LGGs (C-index, training cohort: 0.684; validation cohort: 0.823 ) (55), and demonstrated similar biological processes through radiogenomic analysis.

\section{BRAIN METASTASES}

Approximately $20 \%$ of the cancer patients with other primary sites develop brain metastases, outnumbering primary brain tumors 10:1, but the actual statistic is estimated to be even more since plenty of them do not go through regular MRI examination. The top three extracranial primary cancer types with high intracranial metastatic tendency are lung cancer, breast cancer, and melanoma, which respectively have incidences up to $20-56 \%, 5-20 \%$, and 7-16\% (107-110). Meanwhile, the incidence of brain metastases' occurrence after primary cancer varies according to race, age, and primary cancer. Brain metastases' main symptom is parallel to space occupying lesions, which varies with the lesion location.

\section{Evaluation of Mutation Status}

Since there is inter-heterogeneity between the primary tumor and metastases, assessing the mutation status in the metastases region and comparing with the primary tumor are meaningful in guiding individualized treatment. EGFR inhibitors, such as erlotinib and gefitinib, received distinct responses in GBM and NSCLCs patients originated from different EGFR mutation sites. In NSCLCs, the mutation sites typically locate in the kinase domain that facilitate sensitivity to first-generation EGFR inhibitors. Unlike NSCLCs, the mutation sites of GBMs locate in extracellular domain that promote resistance (111).

Ahn used CE-T1 MRI to predict the EGFR mutation in histologically certified primary lung cancer patients' brain metastases (33 with EGFR WT, 29 with EGFR mutation) (112). Among all the combination of 7 feature selection methods and 4 classification methods, the RF classification model applying RF selection yielded highest AUC of $86.81 \%$ on predicting EGFR mutation status. Subsequent analyses subgrouping BMs by measurable size revealed smaller BMs correlate with better discrimination capacity (AUC $89.09 \%$ in the small BMs subgroup, combining SVM classification with RF selection).

Park used DTI and T1-contrast to classify the EGFR mutation in $99 \mathrm{BMs}$ from 51 NSCLC patients, verified by biopsy. Among all the combinations of 5 feature selection methods and 4 classification methods, the linear discriminant algorithm classifier using 5 features selected by tree-based methods showed the best diagnostic performance, resulting in an AUC of 0.73 (113).

Chen did a retrospective study using CE-T1, T2WI, and FLAIR to predict the mutation on EGFR, ALK, and KRAS mutation in BMs from patients diagnosed primary lung cancer, verified by genotype testing. The model on EGFR, ALK, and KRAS incorporating both radiomics and clinical information resulted in AUC values of 0.912, 0.915, and 0.985 (114).

\section{Identifying Primary Tumor}

The clinical manifestations of BMs are analogous to primary brain tumors. Generally, systemic metastases, cachexia, and multiple foci in CNS may indicate BMs, however, there are up to $15 \%$ with unknown primary tumor (115). Kniep retrospectively studied 189 patients with primary breast cancer, lung cancer (NSCLC and SCLC), gastric cancer, or melanoma, who developed BMs, and analyzed CE-T1 and nonenhanced T1WI and FLAIR through machine learning algorithm (29). The results showed that all the RF classifiers surpassed senior neuroradiologists' reading. After combing radiomics and clinical data, the 5-class model showed best prediction performance with lowest AUC (0.64) for NSCLC and highest AUC (0.82) for melanoma.

\section{Prediction of Recurrence}

As noninvasive treatments such as radiation and chemotherapy have more extensive application in BMs, the most common application of radiomics in BM in recent years may be prediction of treatment and progression.

Prasanna proposed a novel entropy feature called cooccurrence of local anisotropic gradient orientations (COLLAGE) which is of great prognostic value in evaluating radiation necrosis and tumor recurrence on gadolinium-contrast T1WI (116). They proved in 75 patients with metastatic brain tumors that, with additional independent multisite validation, COLLAGE features exhibited statistically significant different skewness $(\mathrm{P}<0.05)$ in recurrent tumor patients compared to patients with pure tumor and cerebral radiation necrosis $>80 \%$.

Huang retrospectively analyzed 161 patients with NSCLC (576 brain metastases) postoperatively by Gamma Knife radiosurgery and found zone percentage related to progression (117). After feature selection by consensus clustering, analysis of univariate Cox proportional hazards model comprising clinical variables, and radiomics features revealed potential prognostic factors that were subsequently selected to build a multivariate Cox proportional hazards model, which indicated that a textural feature called higher zone percentage was independently pertained with higher local tumor control rates (HR 0.712; $\mathrm{P}=$ 0.022). Similar to the result, multivariate proportional hazards model in cause-specific condition also filtered higher zone percentage (HR 0.699; $\mathrm{P}=0.014$ ).

To predict diagnosing treatment effect after stereotactic radiosurgery, Peng investigated 82 lesions of $\mathrm{BM}$ with obvious progression from 66 patients who underwent SRS based on CET1 and T2WI MRI (30). Five top-performing radiomics features out of 51 extracted features filtered by univariate logistic regression were selected to build a subsequent hybrid IsoSVM model, which was assessed by the LOOCV (AUC 0.79). Mouraviev retrospectively analyzed 408 BM lesion in 87 patients who underwent SRS based on their pretreatment CE- 
T1, T2WI, and FLAIR (28). For 440 extracted radiomics features, they applied RF feature importance and ranked these features for selection. The top 12 features comprising radiomics and clinical data are optimized for best prediction model, with the highest AUC (mean $=0.793)$.

\section{LIMITATIONS}

Radiomics is a rapidly expanding field and is still in extensive clinical exploration stage, with many obstacles to overcome. We may discuss the limitations from the aspects of standardization, robustness, repeatability, reproducibility, and generalizability.

Standardization is the basis of robustness, producibility, and generalizability. Current standards lack results validation, incomplete results reports, and unidentified confounding variables in the source database, especially for retrospective data. To solve the above problems and standardize radiomicsspecific reporting, Lambin et al. put forward an evaluation system comprising 16 weighted metrics to determine the workflow completeness, model quality, and clinical adaptation potentiality of radiomics studies, in the form of the radiomics quality score (RQS) (12). The establishment of RQS extended a number of initiatives, such as the Transparent Reporting of a multivariable prediction model for Individual Prognosis OR Diagnosis (TRIPOD) consensus (118).

As is discussed in the Radiogenomics section, radiomics and radiogenomics can only identify the correlation, thus lacking robustness and credibility without tissue biopsy. As for radiomics itself, the accurate segmentation of ROIs is the most challenging step that largely affects the robustness of outcome. Due to a tumor's heterogeneity and polymorphism, manual segmentation is used in most imaging studies. Its advantages are high accuracy and fine delineation of irregular tumor boundaries, but it is greatly affected by subjective factors and is time-consuming and inefficient, with low repeatability. Recently, novel volume data segmentation methods based on deep learning models, such as CNNs named after the shape of the feature map structure (U-net (119) V-net (120), W-net, UNet++ (121) and Y-net), and DeepMedic have made a breakthrough in the clinical radiology segmentation. Current studies demonstrated the utility of CAD, which combines automated brain tumor segmentation with radiomics, in helping physicians to detect following initial observation (122, 123). Most normal tissues like bones and organs can be segmented semi-automatedly or fully automatedly.

However, current protocols of autosegmentation approaches are diverse and lack unified standards. From the studies we reviewed, more intelligent algorithms such as deep learning are rarely used in radiomics of brain tumor compared to lung cancer, prostate cancer, and colorectal cancer. Current segmentation, feature selection, and classification methods in brain tumors are mainly manual operations using shallow machine learning methods, such as random forest, SVM, and LASSO. What's more, the ratio of articles with test-retest analysis is low for currently available original research, which also adds doubts upon repeatability and reproducibility of radiomics analysis. Though the sensitivity, specificity, and/or AUC of the reviewed studies are considerable, few are prospective studies that were later followed up or confirmed by biopsy.

Another problem is that the clinical translation of radiomics studies in multicenter studies faces difficulty in repeatability and reproducibility. For example, MR images may capture noise caused by physiological motion, magnetic field, eddy current, and unsteadiness of the scanning hardware. Then during image reconstruction, noise is post-processed to be wiped out prior to ROIs determination (124). As MR images omit physical parameters, such as magnetic field strength and voxel size, the various settings of image acquisition, reconstruction algorithm, and image processing makes MR radiomics more challenging than CT to ensure repeatability and reproducibility (125-127).

To test the generalizability of prediction model, there are the internal validation and external validation using other centers' data. Current studies in brain tumor still lack big populations, especially from multiple centers. A systematic review by Park et al. evaluated 51 original radiomics research articles in neurooncology with RQS and showed that only $29.4 \%$ performed external validation, with few studies discussing clinical utility and none of them conducting phantom study or cost-effectiveness analysis (128).

There are also ethic problems in that, while the development of AI algorithms requires not only fundamental techniques, but also legislation and perhaps ethics, there are issues on whether researchers or governments should be motivated to share private validated data for machine learning (129). What's more, it is possible for AI algorithms to be tampered with improper intention to make profits.

\section{FURTHER DEVELOPMENTS IN BRAIN TUMOR}

Radiomics accelerates the development of precision medicine. In addition to providing accurate and well-organized personal radiological diagnostic information to identify different states for each patient, large quantities of features extracted from numerous pathologically confirmed patients can contribute a lot to a large-scaled database for tumor classification. The Picture Archiving and Communication System (PACS) has enabled the acquisition, display, processing, storage, transmission, and management of medical images to be digitized and networked in a uniform standard $(130,131)$, with parallel progress in Europe (132) and developing countries (133, 134). Additionally, there are strong public repositories which record these systematic electronic radiological data with open access, for instance, The Cancer Genome Atlas (TCGA) (135), The Cancer Imaging Archive (TCIA) (136), and The Quantitative Imaging Network (QIN) (137).

As the database improves, it can be used for deep learning to evolve over time to build more sophisticated classifiers and may help discover more internal connections between image features and gene expression. Open availability of source code and data is encouraged for current radiomics studies to promote technical development. The development of fully automated approaches based on deep learning will start from solving the most common 
clinical problems with plenty of data (138). These clinical problems may concern occasions where professional neuroradiologists are in heavy demand or analyzation is too cumbersome for neuroradiologists, like predicting $I D H$ mutation status in gliomas (35).

The development of radiomics also compels the development of histopathology. Sampling is a crucial step in identifying the tumor, but it relies on the location of the lesion and is often affected by operator's subjective factors and intra-heterogeneity and inter-heterogeneity of tumor. If radiomics is performed before sampling, it can segment the lesion and suggest the most interesting area so that we can puncture the target tissue accurately. Multicenter radiomic research requires establishing norms for the radiomics study protocols and for their reporting in the literature, which also supplements traditional imaging reports with quantitative indicators and more standard structures.

Based on multiple noninvasive biomarkers, more explicit characteristics of tumor can be assessed, and the progression of tumor can be recorded and visualized (139). For example, liquid biopsy enables the analysis of molecules or macrostructures in low concentration from body liquid that shows minimal invasiveness towards patients who are susceptible to tumor or cannot withstand biopsy. Cucchiara et al. integrated liquid biopsy and radiomics to monitor clonal heterogeneity of EGFR-Positive NSCLC (140). As a result, more individualized treatment plans can be tailored and patients with imperceptible premalignant lesions or who undergo surgery can also benefit, though the expense is another problem to be discussed. Future studies should focus on improving the sensitivity and specificity.

\section{CONCLUSION}

Radiomics was born from traditional radiology, bioinformatics, and machine learning and provides clinicians with economical,

\section{REFERENCES}

1. Siegel RL, Miller KD, Fuchs HE, Jemal A. Cancer Statistics, 2021. CA: Cancer J Clin (2021) 71(1):7-33. doi: 10.3322/caac.21654

2. Zhou M, Scott J, Chaudhury B, Hall L, Goldgof D, Yeom KW, et al. Radiomics in Brain Tumor: Image Assessment, Quantitative Feature Descriptors, and Machine-Learning Approaches. Am J Neuroradiol: AJNR Am Soc Neuroradiol (ASNR) (2018) 39(2):208-16. doi: 10.3174/ajnr.a5391

3. Lambin P, Rios-Velazquez E, Leijenaar R, Carvalho S, van Stiphout RGPM, Granton P, et al. Radiomics: Extracting More Information From Medical Images Using Advanced Feature Analysis. Eur J Cancer (Oxford Engl 1990) (2012) 48(4):441-6. doi: 10.1016/j.ejca.2011.11.036

4. Chaddad A, Kucharczyk MJ, Daniel P, Sabri S, Jean-Claude BJ, Niazi T, et al. Radiomics in Glioblastoma: Current Status and Challenges Facing Clinical Implementation. Front Oncol (2019) 9:374. doi: 10.3389/fonc.2019.00374

5. Gillies RJ, Kinahan PE, Hricak H. Radiomics: Images Are More Than Pictures, They Are Data. Radiology (2016) 278(2):563-77. doi: 10.1148/radiol.2015151169

6. Castellino RA. Computer Aided Detection (CAD): An Overview. Cancer Imaging: Off Publ Int Cancer Imaging Soc e-MED (2005) 5(1):17-9. doi: $10.1102 / 1470-7330.2005 .0018$

7. Nishikawa RM. Computer-Aided Detection and Diagnosis. In: Digital Mammography. Berlin Heidelberg: Springer (2010). p. 85-106. doi: 10.1007/978-3-540-78450-0_6 automatic, and accurate diagnosis on brain tumors by mining high-dimensional data correlated with lesions extracted from images. The overall imaging and evaluating by radiomics not only presents the inner heterogeneity of the lesion but also indicates the microenvironment surrounding the tumor region, making it possible to guide targeted agents before experiment or to be aligned with biopsy to maximize the clinical implications. Though many guidelines are published or being developed, there are still gaps in standard radiomics reporting. As more sophisticated segmentation and analyzation techniques are exploited, along with big data to reach multicenter interoperability, we believe radiomics will soon expand rapidly beyond a small research area and transform into a clinical surrogate diagnosis tool.

\section{AUTHOR CONTRIBUTIONS}

$\mathrm{ZY}$ and YZ reviewed the literature and wrote the manuscript. LL reviewed the literature and generated Table 2. YZ and ZL designed the research. All authors contributed to the article and approved the submitted version.

\section{FUNDING}

The research was funded by China Postdoctoral Science Foundation 2018M643006.

\section{ACKNOWLEDGMENTS}

We are grateful to all of those with whom we have had the pleasure to work with during this and other related projects.

8. Jaffe C. Measures of Response: RECIST, WHO, and New Alternatives. J Of Clin Oncol Amer Soc Clin Oncol (2006) 24(20):3245-51. doi: 10.1200/ JCO.2006.06.5599

9. Schucht P, Knittel S, Slotboom J, Seidel K, Murek M, Jilch A, et al. 5-ALA Complete Resections Go Beyond MR Contrast Enhancement: Shift Corrected Volumetric Analysis of the Extent of Resection in Surgery for Glioblastoma. Acta Neurochirurgica (2014) 156(2):305-12; discussion 312 doi: 10.1007/s00701-013-1906-7

10. Kunz M, Thon N, Eigenbrod S, Hartmann C, Egensperger R, Herms J, et al. Hot Spots in Dynamic (18)FET-PET Delineate Malignant Tumor Parts Within Suspected WHO Grade II Gliomas. Neuro-Oncology (2011) 13 (3):307-16. doi: 10.1093/neuonc/noq196

11. Louis DN, Perry A, Reifenberger G, von Deimling A, Figarella-Branger D, Cavenee WK, et al. The 2016 World Health Organization Classification of Tumors of the Central Nervous System: A Summary. Acta Neuropathol (2016) 131(6):803-20. doi: 10.1007/s00401-016-1545-1

12. Lambin P, Leijenaar RTH, Deist TM, Peerlings J, de Jong EEC, van Timmeren J, et al. Radiomics: The Bridge Between Medical Imaging and Personalized Medicine. Nat Rev Clin Oncol (2017) 14(12):749-62. doi: 10.1038/nrclinonc.2017.141

13. Panth KM, Leijenaar RTH, Carvalho S, Lieuwes NG, Yaromina A, Dubois L, et al. Is There a Causal Relationship Between Genetic Changes and Radiomics-Based Image Features? An In Vivo Preclinical Experiment 
With Doxycycline Inducible GADD34 Tumor Cells. Radiother Oncol: J Eur Soc Ther Radiol Oncol (2015) 116(3):462-6. doi: 10.1016/ j.radonc.2015.06.013

14. Rosenstein BS, West CM, Bentzen SM, Alsner J, Andreassen CN, Azria D, et al. Radiogenomics: Radiobiology Enters the Era of Big Data and Team Science. Int J Radiat Oncol Biol Phys (2014) 89(4):709-13. doi: 10.1016/ j.ijrobp.2014.03.009

15. Rutman AM, Kuo MD. Radiogenomics: Creating a Link Between Molecular Diagnostics and Diagnostic Imaging. Eur J Radiol (2009) 70(2):232-41. doi: 10.1016/j.ejrad.2009.01.050

16. Hu LS, Ning S, Eschbacher JM, Baxter LC, Gaw N, Ranjbar S, et al. Radiogenomics to Characterize Regional Genetic Heterogeneity in Glioblastoma. Neuro-Oncology (2017) 19(1):128-37. doi: 10.1093/neuonc/ now135

17. Zinn PO, Singh SK, Kotrotsou A, Hassan I, Thomas G, Luedi MM, et al. A Coclinical Radiogenomic Validation Study: Conserved Magnetic Resonance Radiomic Appearance of Periostin-Expressing Glioblastoma in Patients and Xenograft Models. Clin Cancer Res an Off J Am Assoc Cancer Res (2018) 24(24):6288-99. doi: 10.1158/1078-0432.CCR-17-3420

18. Kickingereder P, Bonekamp D, Nowosielski M, Kratz A, Sill M, Burth S, et al. Radiogenomics of Glioblastoma: Machine Learning-Based Classification of Molecular Characteristics by Using Multiparametric and Multiregional MR Imaging Features. Radiology (2016) 281(3):907-18. doi: 10.1148/ radiol.2016161382

19. Clauson J, Hsieh YC, Acharya S, Rademaker AW, Morrow M. Results of the Lynn Sage Second-Opinion Program for Local Therapy in Patients With Breast Carcinoma. Changes Manage Determinants Where Care Is Delivered. Cancer (2002) 94(4):889-94. doi: 10.1002/cncr.10318

20. Nguyen PL, Schultz D, Renshaw AA, Vollmer RT, Welch WR, Cote K, et al. The Impact of Pathology Review on Treatment Recommendations for Patients With Adenocarcinoma of the Prostate. Urologic Oncol (2004) 22 (4):295-9. doi: 10.1016/S1078-1439(03)00236-9

21. Sirota RL. Mandatory Second Opinion Surgical Pathology at a Large Referral Hospital. Cancer (2000) 89(1):225-6.

22. Staradub VL, Messenger KA, Hao N, Wiley EL, Morrow M. Changes in Breast Cancer Therapy Because of Pathology Second Opinions. Ann Surg Oncol (2002) 9(10):982-7. doi: 10.1007/BF02574516

23. Sun R, Limkin EJ, Vakalopoulou M, Dercle L, Champiat S, Han SR, et al. A Radiomics Approach to Assess Tumour-Infiltrating CD8 Cells and Response to Anti-PD-1 or Anti-PD-L1 Immunotherapy: An Imaging Biomarker, Retrospective Multicohort Study. Lancet Oncol (2018) 19(9):1180-91. doi: 10.1016/S1470-2045(18)30413-3

24. Trebeschi S, Drago SG, Birkbak NJ, Kurilova I, Călin AM, Delli Pizzi A, et al. Predicting Response to Cancer Immunotherapy Using Noninvasive Radiomic Biomarkers. Ann Oncol: Off J Eur Soc Med Oncol (2019) 30 (6):998-1004. doi: 10.1093/annonc/mdz108

25. Kickingereder P, Götz M, Muschelli J, Wick A, Neuberger U, Shinohara RT, et al. Large-Scale Radiomic Profiling of Recurrent Glioblastoma Identifies an Imaging Predictor for Stratifying Anti-Angiogenic Treatment Response. Clin Cancer Res: an Off J Am Assoc Cancer Res (2016) 22(23):5765-71. doi: 10.1158/1078-0432.CCR-16-0702

26. Ugga L, Cuocolo R, Solari D, Guadagno E, D'Amico A, Somma T, et al. Prediction of High Proliferative Index in Pituitary Macroadenomas Using MRI-Based Radiomics and Machine Learning. Neuroradiology (2019) 61 (12):1365-73. doi: 10.1007/s00234-019-02266-1

27. Niu J, Zhang S, Ma S, Diao J, Zhou W, Tian J, et al. Preoperative Prediction of Cavernous Sinus Invasion by Pituitary Adenomas Using a Radiomics Method Based on Magnetic Resonance Images. Eur Radiol (2019) 29 (3):1625-34. doi: 10.1007/s00330-018-5725-3

28. Peng A, Dai H, Duan H, Chen Y, Huang J, Zhou L, et al. A Machine Learning Model to Precisely Immunohistochemically Classify Pituitary Adenoma Subtypes With Radiomics Based on Preoperative Magnetic Resonance Imaging. Eur J Radiol (2020) 125:108892. doi: 10.1016/ j.ejrad.2020.108892

29. Zhang S, Song G, Zang Y, Jia J, Wang C, Li C, et al. Non-Invasive Radiomics Approach Potentially Predicts non-Functioning Pituitary Adenomas Subtypes Before Surgery. Eur Radiol (2018) 28(9):3692-701. doi: 10.1007/ s00330-017-5180-6
30. Park YW, Eom J, Kim S, Kim H, Ahn SS, Ku CR, et al. Radiomics With Ensemble Machine Learning Predicts Dopamine Agonist Response in Patients With Prolactinoma. J Clin Endocrinol Metab (2021) 106(8): e3069-77. doi: 10.1210/clinem/dgab159

31. Bhayana S, Booth GL, Asa SL, Kovacs K, Ezzat S. The Implication of Somatotroph Adenoma Phenotype to Somatostatin Analog Responsiveness in Acromegaly. J Clin Endocrinol Metab (2005) 90(11):6290-5. doi: 10.1210/ jc.2005-0998

32. Paragliola RM, Corsello SM, Salvatori R. Somatostatin Receptor Ligands in Acromegaly: Clinical Response and Factors Predicting Resistance. Pituitary (2017) 20(1):109-15. doi: 10.1007/s11102-016-0768-4

33. Bakhtiar Y, Hirano H, Arita K, Yunoue S, Fujio S, Tominaga A, et al. Relationship Between Cytokeratin Staining Patterns and ClinicoPathological Features in Somatotropinomae. Eur J Endocrinol (2010) 163 (4):531-9. doi: 10.1530/EJE-10-0586

34. Park YW, Kang Y, Ahn SS, Ku CR, Kim EH, Kim SH, et al. Radiomics Model Predicts Granulation Pattern in Growth Hormone-Secreting Pituitary Adenomas. Pituitary (2020) 23(6):691-700. doi: 10.1007/s11102-02001077-5

35. Fan Y, Liu Z, Hou B, Li L, Liu X, Liu Z, et al. Development and Validation of an MRI-Based Radiomic Signature for the Preoperative Prediction of Treatment Response in Patients With Invasive Functional Pituitary Adenoma. Eur J Radiol (2019) 121:108647. doi: 10.1016/j.ejrad.2019.108647

36. O'Sullivan EP, Woods C, Glynn N, Behan LA, Crowley R, O'Kelly P, et al. The Natural History of Surgically Treated But Radiotherapy-Naive Nonfunctioning Pituitary Adenomas. Clin Endocrinol (2009) 71(5):709-14. doi: 10.1111/j.1365-2265.2009.03583.x

37. Roelfsema F, Biermasz NR, Pereira AM. Clinical Factors Involved in the Recurrence of Pituitary Adenomas After Surgical Remission: A Structured Review and Meta-Analysis. Pituitary (2012) 15(1):71-83. doi: 10.1007/ s11102-011-0347-7

38. Dekkers OM, Hammer S, de Keizer RJW, Roelfsema F, Schutte PJ, Smit JWA, et al. The Natural Course of non-Functioning Pituitary Macroadenomas. Eur J Endocrinol (2007) 156(2):217-24. doi: 10.1530/eje.1.02334

39. Ferrante E, Ferraroni M, Castrignanò T, Menicatti L, Anagni M, Reimondo G, et al. Non-Functioning Pituitary Adenoma Database: A Useful Resource to Improve the Clinical Management of Pituitary Tumors. Eur J Endocrinol (2006) 155(6):823-9. doi: 10.1530/eje.1.02298

40. Zhang Y, Ko C, Chen J, Chang K, Chen T, Lim S, et al. Radiomics Approach for Prediction of Recurrence in Non-Functioning Pituitary Macroadenomas. Front Oncol (2020) 10:590083. doi: 10.3389/fonc.2020.590083

41. Machado LF, Elias PCL, Moreira AC, Dos Santos AC, Murta Junior LO. MRI Radiomics for the Prediction of Recurrence in Patients With Clinically nonFunctioning Pituitary Macroadenomas. Comput Biol Med (2020) 124:103966. doi: 10.1016/j.compbiomed.2020.103966

42. Ostrom QT, Patil N, Cioffi G, Waite K, Kruchko C, Barnholtz-Sloan JS. CBTRUS Statistical Report: Primary Brain and Other Central Nervous System Tumors Diagnosed in the United States in 2013-2017. NeuroOncology (2020) 22(12 Suppl 2):iv1-96. doi: 10.1093/neuonc/noaa200

43. Ostrom QT, Gittleman H, Fulop J, Liu M, Blanda R, Kromer C, et al. CBTRUS Statistical Report: Primary Brain and Central Nervous System Tumors Diagnosed in the United States in 2008-2012. Neuro-oncology Oxford Univ Press (2015) 17 Suppl 4(Suppl 4):iv1-62. doi: 10.1093/ neuonc/nov189

44. Stupp R, Mason WP, van den Bent MJ, Weller M, Fisher B, Taphoorn MJB, et al. Radiotherapy Plus Concomitant and Adjuvant Temozolomide for Glioblastoma. N Engl J Med (2005) 352(10):987-96. doi: 10.1056/ NEJMoa043330

45. Gupta R, Webb-Myers R, Flanagan S, Buckland ME. Isocitrate Dehydrogenase Mutations in Diffuse Gliomas: Clinical and Aetiological Implications. J Clin Pathol (2011) 64(10):835-44. doi: 10.1136/jclinpath2011-200227

46. Lu C, Hsu F, Hsieh KL, Kao YJ, Cheng S, Hsu JB, et al. Machine LearningBased Radiomics for Molecular Subtyping of Gliomas. Clin Cancer Res an Off J Am Assoc (2018) 24(18):4429-36. doi: 10.1158/1078-0432.CCR-17-3445

47. Gutsche R, Scheins J, Kocher M, Bousabarah K, Fink GR, Shah NJ, et al. Evaluation of FET PET Radiomics Feature Repeatability in Glioma Patients. Cancers (2021) 13(4):647. doi: 10.3390/cancers13040647 
48. Choi YS, Bae S, Chang JH, Kang S, Kim SH, Kim J, et al. Fully Automated Hybrid Approach to Predict the IDH Mutation Status of Gliomas via Deep Learning and Radiomics. Neuro-Oncology (2020) 23(2):304-13. doi: $10.1093 /$ neuonc/noaa177

49. Hegi ME, Diserens A, Godard S, Dietrich P, Regli and S. Ostermann L, et al. Clinical Trial Substantiates the Predictive Value of O-6-MethylguanineDNA Methyltransferase Promoter Methylation in Glioblastoma Patients Treated With Temozolomide. Clin Cancer Res an Off J Am Assoc Cancer Res (2004) 10(6):1871-4. doi: 10.1158/1078-0432.ccr-03-0384

50. Wei J, Yang G, Hao X, Gu D, Tan Y, Wang X, et al. A Multi-Sequence and Habitat-Based MRI Radiomics Signature for Preoperative Prediction of MGMT Promoter Methylation in Astrocytomas With Prognostic Implication. Eur Radiol (2019) 29(2):877-88. doi: 10.1007/s00330-0185575-z

51. Li Y, Liu X, Qian Z, Sun Z, Xu K, Wang K, et al. Genotype Prediction of ATRX Mutation in Lower-Grade Gliomas Using an MRI Radiomics Signature. Eur Radiol (2018) 28(7):2960-8. doi: 10.1007/s00330-017-5267-0

52. Haubold J, Demircioglu A, Gratz M, Glas M, Wrede K, Sure U, et al. NonInvasive Tumor Decoding and Phenotyping of Cerebral Gliomas Utilizing. Eur J Nucl Med Mol Imaging (2020) 47(6):1435-45. doi: 10.1007/s00259019-04602-2

53. Su C, Jiang J, Zhang S, Shi J, Xu K, Shen N, et al. Radiomics Based on Multicontrast MRI can Precisely Differentiate Among Glioma Subtypes and Predict Tumour-Proliferative Behaviour. Eur Radiol (2019) 29(4):1986-96. doi: 10.1007/s00330-018-5704-8

54. Chan AK, Pang JC, Chung NY, Li KK, Poon WS, Chan DT, et al. Loss of CIC and FUBP1 Expressions are Potential Markers of Shorter Time to Recurrence in Oligodendroglial Tumors. Modern Pathol an Off J United States Can Acad Pathol Inc (2014) 27(3):332-42. doi: 10.1038/modpathol. 2013.165

55. Gleize V, Alentorn A, Connen de Kérillis L, Labussière M, Nadaradjane AA, Mundwiller E, et al. CIC Inactivating Mutations Identify Aggressive Subset of 1p19q Codeleted Gliomas. Ann Neurol (2015) 78(3):355-74. doi: 10.1002/ ana.24443

56. Padul V, Epari S, Moiyadi A, Shetty P, Shirsat NV. ETV/Pea3 Family Transcription Factor-Encoding Genes are Overexpressed in CIC-Mutant Oligodendrogliomas. Genes Chromosomes Cancer (2015) 54(12):725-33. doi: $10.1002 / \mathrm{gcc} .22283$

57. Zhang L, Giuste F, Vizcarra JC, Li X, Gutman D. Radiomics Features Predict CIC Mutation Status in Lower Grade Glioma. Front Oncol (2020) 10:937. doi: $10.3389 /$ fonc. 2020.00937

58. Brennan CW, Verhaak RGW, McKenna A, Campos B, Noushmehr H, Salama SR, et al. The Somatic Genomic Landscape of Glioblastoma. Cell (2013) 155(2):462-77. doi: 10.1016/j.cell.2013.09.034

59. Binder ZA, Thorne AH, Bakas S, Wileyto EP, Bilello M, Akbari H, et al. Epidermal Growth Factor Receptor Extracellular Domain Mutations in Glioblastoma. Cancer Cell (2018) 34(1):163-77.e7. doi: 10.1016/ j.ccell.2018.06.006

60. Gaonkar B, Davatzikos C. Analytic Estimation of Statistical Significance Maps for Support Vector Machine Based Multi-Variate Image Analysis and Classification. NeuroImage (2013) 78:270-83. doi: 10.1016/ j.neuroimage.2013.03.066

61. Zhou W, Ke SQ, Huang Z, Flavahan W, Fang X, Paul J, et al. Periostin Secreted by Glioblastoma Stem Cells Recruits M2 Tumour-Associated Macrophages and Promotes Malignant Growth. Nat Cell Biol (2015) 17 (2):170-82. doi: 10.1038/ncb3090

62. Malanchi I, Santamaria-Martínez A, Susanto E, Peng H, Lehr H, Delaloye J, et al. Interactions Between Cancer Stem Cells and Their Niche Govern Metastatic Colonization. Nature (2011) 481(7379):85-9. doi: 10.1038/ nature10694

63. Park SY, Piao Y, Jeong KJ, Dong J, de Groot JF. Periostin (POSTN) Regulates Tumor Resistance to Antiangiogenic Therapy in Glioma Models. Mol Cancer Ther (2016) 15(9):2187-97. doi: 10.1158/1535-7163. MCT-15-0427

64. Mikheev AM, Mikheeva SA, Trister AD, Tokita MJ, Emerson SN, Parada CA, et al. Periostin is a Novel Therapeutic Target That Predicts and Regulates Glioma Malignancy. Neuro-Oncology Oxford Univ Press (2015) 17(3):372-82. doi: 10.1093/neuonc/noul61
65. Zinn PO, Singh SK, Kotrotsou A, Hassan I, Thomas G, Luedi MM, et al. A Coclinical Radiogenomic Validation Study: Conserved Magnetic Resonance Radiomic. Clin Cancer Res: An Off J Am Assoc (2018) 24(24):6288-99. doi: 10.1158/1078-0432.CCR-17-3420

66. Frattini V, Pagnotta SM, Tala, Fan JJ, Russo MV, Lee SB, et al. A Metabolic Function of FGFR3-TACC3 Gene Fusions in Cancer. Nature (2018) 553 (7687):222-7. doi: 10.1038/nature25171

67. Di Stefano AL, Picca A, Saragoussi E, Bielle F, Ducray F, Villa C, et al. Clinical, Molecular, and Radiomic Profile of Gliomas With FGFR3-TACC3 Fusions. Neuro-Oncology (2020) 22(11):1614-24. doi: 10.1093/neuonc/ noaa 121

68. Louis DN, Giannini C, Capper D, Paulus W, Figarella-Branger D, Lopes MB, et al. cIMPACT-NOW Update 2: Diagnostic Clarifications for Diffuse Midline Glioma, H3 K27M-Mutant and Diffuse Astrocytoma/Anaplastic Astrocytoma, IDH-Mutant. Acta Neuropathol (2018) 135(4):639-42. doi: 10.1007/s00401-018-1826-y

69. Ryall S, Krishnatry R, Arnoldo A, Buczkowicz P, Mistry M, Siddaway R, et al. Targeted Detection of Genetic Alterations Reveal the Prognostic Impact of H3K27M and MAPK Pathway Aberrations in Paediatric Thalamic Glioma. Acta Neuropathol Commun (2016) 4(1):93. doi: 10.1186/s40478-016-0353-0

70. Ochs K, Ott M, Bunse T, Sahm F, Bunse L, Deumelandt K, et al. K27MMutant Histone-3 as a Novel Target for Glioma Immunotherapy. Oncoimmunology (2017) 6(7):e1328340. doi: 10.1080/2162402X. 2017.1328340

71. Su X, Chen N, Sun H, Liu Y, Yang X, Wang W, et al. Automated Machine Learning Based on Radiomics Features Predicts H3 K27M Mutation in. Neuro-Oncology (2020) 22(3):393-401. doi: 10.1093/neuonc/noz184

72. Cai X, Sughrue ME. Glioblastoma: New Therapeutic Strategies to Address Cellular and Genomic Complexity. Oncotarget (2018) 9(10):9540-54. doi: 10.18632 /oncotarget.23476

73. Park JE, Kim HS, Park SY, Nam SJ, Chun S, Jo Y, et al. Prediction of Core Signaling Pathway by Using Diffusion- and Perfusion-Based MRI. Radiology (2020) 294(2):388-97. doi: 10.1148/radiol.2019190913

74. Abounader R. Interactions between PTEN and Receptor Tyrosine Kinase Pathways and Their Implications for Glioma Therapy. Expert Rev Anticancer Ther (2009) 9(2):235-45. doi: 10.1586/14737140.9.2.235

75. Nakamura JL, Karlsson A, Arvold ND, Gottschalk AR, Pieper RO, Stokoe D, et al. PKB/Akt Mediates Radiosensitization by the Signaling Inhibitor LY294002 in Human Malignant Gliomas. J Neuro-Oncology (2005) 71 (3):215-22. doi: 10.1007/s11060-004-1718-y

76. Li Y, Liang Y, Sun Z, Xu K, Fan X, Li S, et al. Radiogenomic Analysis of PTEN Mutation in Glioblastoma Using Preoperative Multi-Parametric Magnetic Resonance Imaging. Neuroradiology (2019) 61(11):1229-37. doi: 10.1007/s00234-019-02244-7

77. Platta CS, Khuntia D, Mehta MP, Suh JH. Current Treatment Strategies for Brain Metastasis and Complications From Therapeutic Techniques: A Review of Current Literature. Am J Clin Oncol (2010) 33(4):398-407. doi: 10.1097/COC.0b013e318194f744

78. Ohgaki H, Kleihues P. Epidemiology and Etiology of Gliomas. Acta Neuropathol (2005) 109(1):93-108. doi: 10.1007/s00401-005-0991-y

79. Weller M, van den Bent M, Hopkins K, Tonn JC, Stupp R, Falini A, et al. EANO Guideline for the Diagnosis and Treatment of Anaplastic Gliomas and Glioblastoma. Lancet Oncol (2014) 15(9):e395-403. doi: 10.1016/S14702045(14)70011-7

80. Gaudy-Marqueste C, Carron R, Delsanti C, Loundou A, Monestier S, Archier E, et al. On Demand Gamma-Knife Strategy can be Safely Combined With BRAF Inhibitors for the Treatment of Melanoma Brain Metastases. Ann Oncol (2014) 25(10):2086-91. doi: 10.1093/annonc/ mdu266

81. Qian Z, Li Y, Wang Y, Li L, Li R, Wang K, et al. Differentiation of Glioblastoma From Solitary Brain Metastases Using Radiomic. Cancer Lett (2019) 451:128-35. doi: 10.1016/j.canlet.2019.02.054

82. Kang D, Park JE, Kim Y, Kim JH, Oh JY, Kim J, et al. Diffusion Radiomics as a Diagnostic Model for Atypical Manifestation of Primary. Neuro-Oncology (2018) 20(9):1251-61. doi: 10.1093/neuonc/noy021

83. Wu G, Chen Y, Wang Y, Yu J, Lv X, Ju X, et al. Sparse Representation-Based Radiomics for the Diagnosis of Brain Tumors. IEEE Trans Med Imaging (2018) 37(4):893-905. doi: 10.1109/TMI.2017.2776967 
84. Elshafeey N, Kotrotsou A, Hassan A, Elshafei N, Hassan I, Ahmed S, et al. Multicenter Study Demonstrates Radiomic Features Derived From Magnetic Resonance. Nat Commun (2019) 10(1):3170. doi: 10.1038/s41467-01911007-0

85. Lohmann P, Elahmadawy MA, Gutsche R, Werner J, Bauer EK, Ceccon G, et al. FET PET Radiomics for Differentiating Pseudoprogression From Early Tumor Progression in Glioma Patients Post-Chemoradiation. Cancers (2020) 12(12):3835. doi: 10.3390/cancers12123835

86. Kim JY, Park JE, Jo Y, Shim WH, Nam SJ, Kim JH, et al. Incorporating Diffusion- and Perfusion-Weighted MRI Into a Radiomics Model Improves. Neuro-Oncology (2019) 21(3):404-14. doi: 10.1093/neuonc/noyl33

87. Wang K, Qiao Z, Zhao X, Li X, Wang X, Wu T, et al. Individualized Discrimination of Tumor Recurrence From Radiation Necrosis in Glioma. Eur J Nucl Med Mol Imaging (2020) 47(6):1400-11. doi: 10.1007/s00259019-04604-0

88. Chao ST, Ahluwalia MS, Barnett GH, Stevens GHJ, Murphy ES, Stockham $\mathrm{AL}$, et al. Challenges With the Diagnosis and Treatment of Cerebral Radiation Necrosis. Int J Radiat Oncol Biol Phys (2013) 87(3):449-57. doi: 10.1016/j.ijrobp.2013.05.015

89. Xu Y, Rong X, Hu W, Huang X, Li Y, Zheng D, et al. Bevacizumab Monotherapy Reduces Radiation-Induced Brain Necrosis in Nasopharyngeal Carcinoma Patients: A Randomized Controlled Trial. Int J Radiat Oncol Biol Phys (2018) 101(5):1087-95. doi: 10.1016/ j.ijrobp.2018.04.068

90. Cai J, Zheng J, Shen J, Yuan Z, Xie M, Gao M, et al. A Radiomics Model for Predicting the Response to Bevacizumab in Brain Necrosis After Radiotherapy. Clin Cancer Res: an Off J Am Assoc Cancer Res (2020) 26 (20):5438-47. doi: 10.1158/1078-0432.CCR-20-1264

91. Aslan K, Turco V, Blobner J, Sonner JK, Liuzzi AR, Núñez NG, et al. Heterogeneity of Response to Immune Checkpoint Blockade in Hypermutated Experimental Gliomas. Nat Commun (2020) 11(1):931. doi: 10.1038/s41467-020-14642-0

92. Stupp R, Hegi ME, Mason WP, van den Bent MJ, Taphoorn MJB, Janzer RC, et al. Effects of Radiotherapy With Concomitant and Adjuvant Temozolomide Versus Radiotherapy Alone on Survival in Glioblastoma in a Randomised Phase III Study: 5-Year Analysis of the EORTC-NCIC Trial. Lancet Oncol (2009) 10(5):459-66. doi: 10.1016/S1470-2045(09)70025-7

93. Scott JG, Berglund A, Schell MJ, Mihaylov I, Fulp WJ, Yue B, et al. A Genome-Based Model for Adjusting Radiotherapy Dose (GARD): A Retrospective, Cohort-Based Study. Lancet Oncol (2017) 18(2):202-11. doi: 10.1016/S1470-2045(16)30648-9

94. Pan Z, Zhang S, Wang X, Jiao Y, Qiu J. Machine Learning Based on a Multiparametric and Multiregional Radiomics Signature Predicts Radiotherapeutic Response in Patients With Glioblastoma. Behav Neurol (2020) 2020:1712604. doi: 10.1155/2020/1712604

95. Dastmalchian S, Kilinc O, Onyewadume L, Tippareddy C, McGivney D, Ma D, et al. Radiomic Analysis of Magnetic Resonance Fingerprinting in Adult Brain Tumors. Eur J Nucl Med Mol Imaging (2020) 48(3):683-93. doi: 10.1007/s00259-020-05037-w

96. Bae S, Choi YS, Ahn SS, Chang JH, Kang S, Kim EH, et al. Radiomic MRI Phenotyping of Glioblastoma: Improving Survival Prediction. Radiology (2018) 289(3):797-806. doi: 10.1148/radiol.2018180200

97. Papp L, Pötsch N, Grahovac M, Schmidbauer V, Woehrer A, Preusser M, et al. Glioma Survival Prediction With Combined Analysis of In Vivo (11)CMET PET Features. J Nucl Med Off Publication Soc Nucl Med (2018) 59 (6):892-9. doi: 10.2967/jnumed.117.202267

98. Beig N, Singh S, Bera K, Prasanna P, Singh G, Chen J, et al. Sexually Dimorphic Radiogenomic Models Identify Distinct Imaging and Biological Pathways That Are Prognostic of Overall Survival in Glioblastoma. NeuroOncology (2021) 23(2):251-63. doi: 10.1093/neuonc/noaa231

99. Verduin M, Primakov S, Compter I, Woodruff HC, van Kuijk SMJ, Ramaekers BLT, et al. Prognostic and Predictive Value of Integrated Qualitative and Quantitative Magnetic Resonance Imaging Analysis in Glioblastoma. Cancers (2021). doi: 10.3390/cancers13040722

100. Kickingereder P, Neuberger U, Bonekamp D, Piechotta PL, Götz M, Wick A, et al. Radiomic Subtyping Improves Disease Stratification Beyond Key Molecular, Clinical. Neuro-Oncology (2018) 20(6):848-57. doi: 10.1093/ neuonc/nox 188
101. Wang Y, Wei W, Liu Z, Liang Y, Liu X, Li Y, et al. Predicting the Type of Tumor-Related Epilepsy in Patients With Low-Grade Gliomas: A Radiomics Study. Front In Oncol (2020) 10:235. doi: 10.3389/fonc.2020.00235

102. Qian Z, Li Y, Sun Z, Fan X, Xu K, Wang K, et al. Radiogenomics of LowerGrade Gliomas: A Radiomic Signature as a Biological Surrogate for Survival Prediction. Aging (2018) 10(10):2884-99. doi: 10.18632/aging.101594

103. Liu X, Li Y, Qian Z, Sun Z, Xu K, Wang K, et al. A Radiomic Signature as a non-Invasive Predictor of Progression-Free Survival in Patients With LowerGrade Gliomas. NeuroImage. Clin (2018) 20:1070-7. doi: 10.1016/ j.nicl.2018.10.014

104. Nayak L, Lee EQ, Wen PY. Epidemiology of Brain Metastases. Curr Oncol Rep (2012) 14(1):48-54. doi: 10.1007/s11912-011-0203-y

105. Berghoff AS, Schur S, Füreder LM, Gatterbauer B, Dieckmann K, Widhalm G, et al. Descriptive Statistical Analysis of a Real-Life Cohort of 2419 Patients With Brain Metastases of Solid Cancers. ESMO Open (2016) 1(2):e000024.

106. Sperduto PW, Chao ST, Sneed PK, Luo X, Suh J, Roberge D, et al. DiagnosisSpecific Prognostic Factors, Indexes, and Treatment Outcomes for Patients With Newly Diagnosed Brain Metastases: A Multi-Institutional Analysis of 4,259 Patients. Int J Radiat Oncol Biol Phys (2010) 77(3):655-61. doi: 10.1016/j.ijrobp.2009.08.025

107. Barnholtz-Sloan JS, Sloan AE, Davis FG, Vigneau FD, Lai P, Sawaya RE. Incidence Proportions of Brain Metastases in Patients Diagnosed (1973 to 2001) in the Metropolitan Detroit Cancer Surveillance System. J Clin Oncol Off J Am Soc Clin Oncol (2004) 22(14):2865-72. doi: 10.1200/ JCO.2004.12.149

108. Vivanco I, Robins HI, Rohle D, Campos C, Grommes C, Nghiemphu PL, et al. Differential Sensitivity of Glioma- Versus Lung Cancer-Specific EGFR Mutations to EGFR Kinase Inhibitors. Cancer Discov (2012) 2(5):458-71. doi: 10.1158/2159-8290.CD-11-0284

109. Ahn S, Kwon H, Yang J, Park M, Cha Y, Suh S, et al. Contrast-Enhanced T1Weighted Image Radiomics of Brain Metastases may Predict EGFR Mutation Status in Primary Lung Cancer. Sci Rep (2020) 10(1):8905. doi: 10.1038/ s41598-020-65470-7

110. Park Y, An C, Lee J, Han K, Choi D, Ahn S, et al. Diffusion Tensor and Postcontrast T1-Weighted Imaging Radiomics to Differentiate the Epidermal Growth Factor Receptor Mutation Status of Brain Metastases From nonSmall Cell Lung Cancer. Neuroradiology (2020) 63(3):343-52. doi: 10.1007/ s00234-020-02529-2

111. Chen B, Jin T, Ye N, Mambetsariev I, Daniel E, Wang T, et al. Radiomic Prediction of Mutation Status Based on MR Imaging of Lung Cancer Brain Metastases. Magn Reson Imaging (2020) 69:49-56. doi: 10.1016/ j.mri.2020.03.002

112. Balestrino R, Rudà R, Soffietti R. Brain Metastasis From Unknown Primary Tumour: Moving From Old Retrospective Studies to Clinical Trials on Targeted Agents. Cancers (2020) 12(11):3350. doi: 10.3390/cancers12113350

113. Kniep H, Madesta F, Schneider T, Hanning U, Schonfeld M, Schon G, et al. Radiomics of Brain MRI: Utility in Prediction of Metastatic Tumor Type. Radiol Radiol Soc North Am (2019) 290(2):479-87. doi: 10.1148/ radiol.2018180946

114. Prasanna P, Rogers L, Lam T, Cohen M, Siddalingappa A, Wolansky L, et al. Disorder in Pixel-Level Edge Directions on T1WI Is Associated With the Degree of Radiation Necrosis in Primary and Metastatic Brain Tumors: Preliminary Findings. Am J Of Neuroradiol Amer Soc Neuroradiol (2019) 40 (3):412-7. doi: 10.3174/ajnr.A5958

115. Huang C, Lee C, Yang H, Lin C, Wu H, Chung W, et al. Radiomics as Prognostic Factor in Brain Metastases Treated With Gamma Knife Radiosurgery. J Of Neuro-Oncology (2020) 146(3):439-49. doi: 10.1007/ s11060-019-03343-4

116. Peng L, Parekh V, Huang P, Lin D, Sheikh K, Baker B, et al. Distinguishing True Progression From Radionecrosis After Stereotactic Radiation Therapy for Brain Metastases With Machine Learning and Radiomics. Int $J$ Of Radiat Oncol Biol Phys (2018) 102(4):1236-43. doi: 10.1016/j.ijrobp.2018.05.041

117. Mouraviev A, Detsky J, Sahgal A, Ruschin M, Lee Y, Karam I, et al. Use of Radiomics for the Prediction of Local Control of Brain Metastases After Stereotactic Radiosurgery. Neuro-Oncology (2020) 22(6):797-805. doi: 10.1093/neuonc/noaa007

118. Collins GS, Reitsma JB, Altman DG, Moons KGM. Transparent Reporting of a Multivariable Prediction Model for Individual Prognosis Or 
Diagnosis (TRIPOD). Ann Internal Med (2015) 162(10):735-6. doi: 10.7326/ L15-5093-2

119. Ronneberger O, Fischer P, Brox T. U-Net: Convolutional Networks for Biomedical Image Segmentation, Medical Image Computing and ComputerAssisted Intervention - MICCAI 2015. In: Lecture Notes in Computer Science, vol. 9351. Cham: Springer (2015). doi: 10.1007/978-3-319-24574$4 \_28$

120. Milletari F, Navab N, Ahmadi S. (2016). V-Net: Fully Convolutional Neural Networks for Volumetric Medical Image Segmentation, in: 2016 Fourth International Conference on 3D Vision (3DV), . pp. 565-71. doi: 10.1109/ 3DV.2016.79

121. Zhou Z, Siddiquee MMR, Tajbakhsh N, Liang J. UNet++: A Nested U-Net Architecture for Medical Image Segmentation. Deep Learning in Medical Image Analysis and Multimodal Learning for Clinical Decision Support : 4th International Workshop, DLMIA 2018, and 8th International Workshop, ML-CDS 2018, Held in Conjunction With MICCAI 2018 Vol. 11045. Granada, Spain, S (2018) p. 3-11. doi: 10.1007/978-3-030-00889-5_1

122. Chen W, Liu B, Peng S, Sun J, Qiao X. Computer-Aided Grading of Gliomas Combining Automatic Segmentation and Radiomics. Int J Biomed Imaging (2018) 2018:2512037. doi: 10.1155/2018/2512037

123. Fathallah-Shaykh HM, DeAtkine A, Coffee E, Khayat E, Bag AK, Han X, et al. Diagnosing Growth in Low-Grade Gliomas With and Without Longitudinal Volume Measurements: A Retrospective Observational Study. PloS Med (2019) 16(5):e1002810. doi: 10.1371/journal.pmed.1002810

124. You X, Cao N, Lu H, Mao M, Wang W. Denoising of MR Images With Rician Noise Using a Wider Neural Network and Noise Range Division. Magn Reson Imaging (2019) 64:154-9. doi: 10.1016/j.mri.2019.05.042

125. Zwanenburg A. Radiomics in Nuclear Medicine: Robustness, Reproducibility, Standardization, and How to Avoid Data Analysis Traps and Replication Crisis. Eur J Nucl Med Mol Imaging (2019) 46(13):2638-55. doi: 10.1007/s00259-019-04391-8

126. Mayerhoefer ME, Materka A, Langs G, Häggström I, Szczypiński P, Gibbs P, et al. Introduction to Radiomics. J Nucl (2020) 61(4):488-95. doi: 10.2967/ jnumed.118.222893

127. Yang F, Dogan N, Stoyanova R, Ford JC. Evaluation of Radiomic Texture Feature Error Due to MRI Acquisition and Reconstruction: A Simulation Study Utilizing Ground Truth. Physica Med (2018) 50:26-36. doi: 10.1016/ j.ejmp.2018.05.017

128. Park JE, Kim HS, Kim D, Park SY, Kim JY, Cho SJ, et al. A Systematic Review Reporting Quality of Radiomics Research in Neuro-Oncology: Toward Clinical Utility and Quality Improvement Using High-Dimensional Imaging Features. BMC Cancer BioMed Cent (2020) 20(1):29. doi: $10.1186 / \mathrm{s} 12885-019-6504-5$

129. Chang K, Balachandar N, Lam C, Yi D, Brown J, Beers A, et al. Distributed Deep Learning Networks Among Institutions for Medical Imaging. J Am Med Inf Association: JAMIA (2018) 25(8):945-54. doi: 10.1093/jamia/ocy017

130. Bryan S, Weatherburn G, Watkins J, Roddie M, Keen J, Muris N, et al. Radiology Report Times: Impact of Picture Archiving and Communication Systems. AJR Am J Roentgenol (1998) 170(5):1153-9. doi: 10.2214/ ajr.170.5.9574575

131. Mansoori B, Erhard KK, Sunshine JL. Picture Archiving and Communication System (PACS) Implementation, Integration \& Benefits in an Integrated Health System. Acad Radiol (2012) 19(2):229-35. doi: $10.1016 /$ j.acra.2011.11.009

132. Lemke HU. PACS Developments in Europe. Computerized Med Imaging Graphics: Off J Computerized Med Imaging Soc (2003) 27(2-3):111-20. doi: 10.1016/s0895-6111(02)00084-8

133. Sarbaz M, Hosseini N, Kimiafar K. Views of Users Towards the Quality of Picture Archiving and Communication System (PACS) in a Developing Country. Stud Health Technol Inf (2019) 258:100-4.

134. Elahi A, Dako F, Zember J, Ojetayo B, Gerus DA, Schweitzer A, et al. Overcoming Challenges for Successful PACS Installation in Low-Resource Regions: Our Experience in Nigeria. J Digital Imaging (2020) 33(4):9961001. doi: 10.1007/s10278-020-00352-y

135. Cancer Genome Atlas Research Network. Comprehensive Genomic Characterization Defines Human Glioblastoma Genes and Core Pathways. Nature (2008) 455(7216):1061-8. doi: 10.1038/nature07385

136. Prior FW, Clark K, Commean P, Freymann J, Jaffe C, Kirby J, et al. TCIA: An Information Resource to Enable Open Science. in: Annual International Conference of the IEEE Engineering in Medicine and Biology Society. IEEE Engineering in Medicine and Biology Society. Annual International Conference. (2013) 2013:1282-5. doi: 10.1109/EMBC.2013.6609742

137. Kalpathy-Cramer J, Freymann JB, Kirby JS, Kinahan PE, Prior FW. Quantitative Imaging Network: Data Sharing and Competitive AlgorithmValidation Leveraging The Cancer Imaging Archive. Trans Oncol (2014) 7(1):147-52. doi: 10.1593/tlo.13862

138. Hosny A, Parmar C, Quackenbush J, Schwartz LH, Aerts HJWL. Artificial Intelligence in Radiology. Nat Rev Cancer (2018) 18(8):500-10. doi: 10.1038/ s41568-018-0016-5

139. Yousefi B, LaRiviere MJ, Cohen EA, Buckingham TH, Yee SS, Black TA, et al. Combining Radiomic Phenotypes of Non-Small Cell Lung Cancer With Liquid Biopsy Data may Improve Prediction of Response to EGFR Inhibitors. Sci Rep (2021) 11(1):9984. doi: 10.1038/s41598-021-88239-y

140. Cucchiara F, Petrini I, Romei C, Crucitta S, Lucchesi M, Valleggi S, et al. Combining Liquid Biopsy and Radiomics for Personalized Treatment of Lung Cancer Patients. State Art New Perspectives. Pharmacol Res (2021) 169:105643. doi: 10.1016/j.phrs.2021.105643

Conflict of Interest: The authors declare that the research was conducted in the absence of any commercial or financial relationships that could be construed as a potential conflict of interest.

Publisher's Note: All claims expressed in this article are solely those of the authors and do not necessarily represent those of their affiliated organizations, or those of the publisher, the editors and the reviewers. Any product that may be evaluated in this article, or claim that may be made by its manufacturer, is not guaranteed or endorsed by the publisher.

Copyright (c) $2021 \mathrm{Yi}$, Long, Zeng and Liu. This is an open-access article distributed under the terms of the Creative Commons Attribution License (CC BY). The use, distribution or reproduction in other forums is permitted, provided the original author(s) and the copyright owner(s) are credited and that the original publication in this journal is cited, in accordance with accepted academic practice. No use, distribution or reproduction is permitted which does not comply with these terms. 